\title{
Persistent Infection of Human Mesenchymal Stromal Cells With Bartonella Henselae Exerts a Proangiogenic Effect
}

\section{Sara Scutera}

University of Turin: Universita degli Studi di Torino https://orcid.org/0000-0002-7431-0875

\section{Stefania Mitola}

University of Brescia: Universita degli Studi di Brescia

\section{Rosaria Sparti}

Università degli Studi di Torino: Universita degli Studi di Torino

\section{Giorgia Piersigilli}

Università degli Studi di Torino: Universita degli Studi di Torino

\section{Elisabetta Grillo}

University of Brescia: Universita degli Studi di Brescia

\section{Mattia Bugatti}

Università degli Studi di Brescia: Universita degli Studi di Brescia

\section{Valentina Salvi}

Università degli Studi di Brescia: Universita degli Studi di Brescia

\section{Daniela Alotto}

Azienda Ospedaliero Universitaria Città della Salute e della Scienza di Torino: Azienda Ospedaliero Universitaria Citta della Salute e della Scienza di Torino

\section{Tiziana Schioppa}

University of Brescia: Universita degli Studi di Brescia

\section{Tiziana Musso ( $\square$ tiziana.musso@unito.it)}

Department of Public Health and Pediatric Sciences, University of Torino, Italy.

\section{Silvano Sozzani}

University of Rome La Sapienza: Universita degli Studi di Roma La Sapienza

\section{Research}

Keywords: Mesemchymal stromal cells, B. henselae, angiogenesis, EGFR, TLR, NOD

Posted Date: December 10th, 2020

DOI: https://doi.org/10.21203/rs.3.rs-122499/v1 
License: (c) (i) This work is licensed under a Creative Commons Attribution 4.0 International License. Read Full License 
1 TITLE

2 Persistent Infection of Human Mesenchymal Stromal Cells with Bartonella henselae Exerts a

3 Proangiogenic Effect

4

5 Scutera Sara $^{1^{*}}$ Mitola Stefania ${ }^{2^{*}}$ Sparti Rosaria $^{1}$ Piersigilli Giorgia $^{1}$ Grillo Elisabetta $^{2}$ Bugatti

6 Mattia $^{2}$ Salvi Valentina ${ }^{2}$ Alotto Daniela ${ }^{3}$ Schioppa Tiziana $^{2}$ Musso Tiziana $^{1 \#}$ Sozzani Silvano $^{4}$

$7 \quad$ Contributed equally

$8 \quad$ \# Corresponding author

9 Affiliations

$10{ }^{1}$ Department of Public Health and Pediatric Sciences, University of Torino, Italy.

$11{ }^{2}$ Department of Molecular and Translational Medicine, University of Brescia, Italy.

$12 \quad{ }^{3}$ Skin Bank, Department of General and Specialized Surgery, A.O.U. Città della Salute e della 13 Scienza, Turin, Italy.

$14{ }^{4}$ Laboratory Affiliated to Istituto Pasteur Italia-Fondazione Cenci Bolognetti, Department of

15 Molecular Medicine, Sapienza University of Rome, Italy.

16 Correspondence

17 Tiziana Musso tiziana.musso@unito.it 


\section{ABSTRACT}

\section{Background}

$B$ henselae is in humans the aetiologic agent of cat-scratch disease and of the vasculoproliferative disorders bacillary angiomatosis and bacillary peliosis. Although endothelial cells are crucial in the pathogenesis other cell types function as reservoir and contribute to pathological angiogenesis. Among them, mesenchymal stromal cells (MSCs) can sense pathogens and mount an appropriate cytokine/chemokine response through different Pattern Recognition Receptors (PRRs). MSCs exert direct antimicrobial effector function but may also shelter bacteria such as M. tuberculosis.

\section{Methods}

Adipose-derived MSCs were infected with $B$. henselae and analyzed for bacterial persistence by gentamicin protection assay, immunohistochemistry and immunofluorescence. Involvement of PRRs in bacterial infection was evaluated through gene and protein expression analysis. The effect of infection on MSC proliferation, apoptosis and release of soluble factors was assessed. The role of infected-MSC conditioned medium in promoting Bartonella infection of endothelial cells and angiogenesis was demonstrated using respectively gentamicin protection assay and different proangiogenic assays including spheroid, wound healing and morphogenesis.

\section{Results}

B. henselae can readily infect MSCs and survive in perinuclear bound vacuoles for up to 8 days. Bartonella infection stimulates MSC proliferation and upregulation of EGFR and of the two pattern recognition receptors (PRRs) TLR2 and NOD1. Specific inhibition of EGFR reduces bacterial internalization and treatment with anti-TLR2 neutralizing antibody or EGFR/NOD1 inhibitors significantly downmodulates CXCL8 production. Secretome analysis shows that, in addition to CXCL8, infected MSCs secrete higher levels of the proangiogenic factors VEGF, FGF-7, MMP-9, PIGF, serpin E1, TSP-1, uPA, IL-6, CCL5 and PDGF-D. Importantly, supernatants from $B$. henselae-infected MSCs increase the susceptibility of ECs to B. henselae infection while enhancing 
EC proangiogenic potential.

\section{Conclusions}

Altogether, these findings indicate that MSCs constitute a novel niche for $B$. henselae, which favors the persistence of vascular proliferative disorders.

\section{KEYWORDS}

Mesemchymal stromal cells, $B$. henselae, angiogenesis, EGFR, TLR, NOD

\section{BACKGROUND}

Endemic among domestic cats, $B$. henselae is a fastidious gram-negative bacterium that, in humans, can cause subclinical intraerythrocytic bacteremia, mainly transmitted by cat fleas. In immunocompetent individuals, $B$. henselae infection can also lead to cat-scratch disease (CSD), characterized by lymphadenopathy with suppurative granulomas. Atypical clinical presentations of $\mathrm{CSD}$, ranging from prolonged fever of unknown origin to hepatosplenic, ocular and neurological manifestations, have also been reported [1].

Individuals unable to mount an immune response against $B$. henselae tend to develop a tumor-like vascular proliferative response in the skin and/or internal organs, which can lead to bacillary angiomatosis (BA) or bacillary peliosis (BP) [2]. Interestingly, B. henselae survive in human endothelial cells (ECs) and stimulate their migration, proliferation and secretion of various proinflammatory and proangiogenic factors, such as ICAM-1, angiopoietin-2, IL-8 and MCP-1 [25]. In addition, other cells types, such as monocytes/macrophages [6] are recruited to the vasoproliferative lesions where they stimulate EC proliferation in a paracrine manner through VEGF and IL-8 secretion [7]. Moreover, macrophages and DCs localized in the skin at the site of infection-play a role in transporting Bartonella species to endothelium [7]. Of note, mononuclear phagocytes, $\mathrm{CD} 34^{+}$progenitor cells and ECs can provide an infection reservoir from which $B$. henselae periodically reaches the bloodstream and disseminates within the host [8]. Despite the 
clinical implications of protracted Bartonella infections, the underlying mechanism of intracellular B. henselae persistence is poorly understood, and the existence of different reservoirs still remains to be determined.

Mesenchymal stem cells (MSCs) are multipotent adult stem cells present in various tissues, including the bone marrow and the adipose tissue, which have recently received much attention due to their regenerative potential and immunomodulatory properties [9]. In addition, MSCs modulate the tissue vascularization both through direct contact and indirect signaling [10,11].

A diverse and multitasking role of MSCs during bacterial infection has recently emerged [12,13]. MSCs can sense pathogens and mount an appropriate cytokine/chemokine response through Toll-like receptors (TLRs), NOD-like receptors (NLRs) and the scavenger receptors MARCO and SR-B1 [12]. Moreover, MSCs express EGFR, a (member of the ErbB receptor tyrosine kinase family), shown to enhance their proliferation and the release of angiogenic factors [14]. Interestingly, ErB receptors can be exploited by a wide range of microbes to facilitate their cellular entry and subvert host immunity [15]. However, despite the emerging role of MSCs in infectious diseases, the mechanisms regulating the interplay between MSCs and bacteria are yet to be defined. MSCs exert antimicrobial effects by secreting antimicrobial peptides (AMPs) and expressing the anti-inflammatory factor indoleamine2,3-dioxygenase (IDO)[16,17]. Furthermore, MSC administration appears to reduce pathogen burden in animal models of polymicrobial sepsis and pneumonia [18-21]. On the other hand, MSCs serve as a niche where M. tuberculosis can survive and persist during antimicrobial therapy. Indeed, viable $M$. tuberculosis was recovered from MSCs infiltrating TB granulomas in humans and in a tuberculosis mouse model [22,23]. Thus, it is likely that other pathogens, besides $M$. tuberculosis, known to cause chronic infections, may similarly exploit MSCs to favor their persistence in the host.

In this study, we show that $B$. henselae can readily infect human MSCs and survive in these cells for a prolonged period, promoting the release of proinflammatory and proangiogenic factors through a novel signaling pathway involving TLR2, NOD1 and EGFR. 
METHODS

Reagents and antibodies. MTT 3-(4,5-dimethylthiazol-2-yl)-2,5-diphenyltetrazolium

bromide was purchase from Sigma Aldrich (MO, USA). The EGFR inhibitor gefitinib and RIPK2 inhibitor GSK583 were purchase from MedChemExpress (NJ, USA). The neutralizing antibody anti-TLR2 (anti-human TLR2-IgA, clone B4H2) and the human IgA2 Isotype control were both purchased from InvivoGen (CA, USA). The neutralizing antibody anti-EGFR (mouse IgG1, clone LA1) and its specific isotype control were from EMD Millipore Corporation (CA, USA). Recombinant human VEGF-A 165 and EGF were from R\&D System (MN, USA). The Protease Inhibitor Cocktail and the Phosphatase Inhibitor Cocktail were from Sigma Aldrich. The rabbit poly anti-B. henselae monoclonal antibody (anti-BH; mouse $\mathrm{IgG} 2 \mathrm{~b} /$ clone $\mathrm{H} 2 \mathrm{~A} 10$ ) was purchased from Abcam (Cambridge, United Kingdom), whereas the biotinylated secondary IgG antibodies were from Agilent (CA, USA). The antibodies against EGFR (clone A10, sc-373746), pY1068-EGFR (sc-377547) and secondary antibodies HRP-conjugated were from Santa Cruz Biotechnology, Inc. (Texas, USA). The wheat germ agglutinin-Alexa Fluor 594 or 488 conjugate, Alexa Fluor ${ }^{\circledR} 594$ phalloidin (A12381), goat anti-Mouse Alexa Fluor ${ }^{\circledR} 488$ conjugate, goat anti-Rabbit Alexa Fluor ${ }^{\circledR}$ 594 conjugate and DAPI (4',6-diamidin-2-fenilindolo) were all from ThermoFisher Scientific (CA, USA). The anti-human TLR-2 FITC (mouse IgG2a) and anti-human TLR-4 PE (mouse IgG2a) or respective isotype control were from BioLegend (CA, USA).

Cell culture. Human MSCs were isolated from adipose tissues as previously described [24]. Human adipose tissues were collected by lipoaspiration from healthy donors after written consent and in compliance with the Declaration of Helsinki and the local Ethic Committee (Comitato Etico Interaziendale A.O.U. Città della Salute e della Scienza di Torino - A.O. Ordine Mauriziano - ASL TO1, No. 0009806). Subsequently, MSCs were analyzed by flow cytometry to verify their phenotype was positive for CD73, CD90 and CD105 and negative for CD11b, CD34 and CD45. HUVECs were isolated from umbilical cords of healthy informed volunteers in compliance 
with the Declaration of Helsinki. HUVECs were used at early (I-IV) passages and grown on culture plates coated with porcine gelatin in M199 medium (Gibco Life Technologies, ThermoFisher Scientific Group) supplemented with $20 \%$ heat-inactivated fetal calf serum (FCS, Gibco Life Technologies), endothelial cell growth factor (ECGF) $(10 \mu \mathrm{g} / \mathrm{mL})$, and porcine heparin (100 $\mu \mathrm{g} / \mathrm{mL})$ (Sigma Aldrich) $(100 \mu \mathrm{g} / \mathrm{mL})$ or in complete EBM2 medium (Lonza Group Ltd Basel, Switzerland).

Bacterial cultures. B. henselae Houston I strain (ATCC 49882; Manassas, VA, USA) was grown on $5 \%$ sheep blood Columbia agar plates (BioMerieux, Lyon, France) under anaerobic conditions (i.e., candle jar) at $37^{\circ} \mathrm{C}$ for 10 days. Bacteria were harvested under a laminar-flow hood by gently scraping colonies off the agar surface. They were then suspended in MICROBANK ${ }^{\mathrm{TM}}$ cryopreservative solution and stored at $-80^{\circ} \mathrm{C}$ in $1-\mathrm{mL}$ aliquots. For biological assays, frozen bacteria were incubated in Schneider's Insect Medium (Sigma-Aldrich) supplemented with 10\% FBS at $37^{\circ} \mathrm{C}$ and $5 \% \mathrm{CO}_{2}$ for 6 days. Spectrophotometry was performed to evaluate bacterial growth [optical density (OD600) 0.6 , corresponding to $1 \times 10^{8}$ bacteria/mL] and confirmed by plating serial dilutions on 5\% sheep blood Columbia agar plates. Bacteria, washed 3 times with $1 \mathrm{X}$ PBS, were then added to cell cultures. Where indicated, $B$. henselae were killed by heating thawed bacteria at $56^{\circ} \mathrm{C}$ for $30 \mathrm{~min}$.

Infection assay. B. henselae invasion of MSCs was assessed by GPA. Briefly, 12,500 cells $/ \mathrm{cm}^{2}$ MSCs were seeded for $24 \mathrm{~h}$ in RPMI supplemented with 10\% FCS. To compare MSCs with HUVECs, infection was carried out with 60,000 cells per well seeded in DMEM 10\% FCS or complete EBM2 medium (Lonza Group Ltd), respectively. The next day, cells were washed twice and cultured in RPMI supplemented with $10 \%$ FCS without antibiotics. B. henselae (MOI 10-50100) was added to the cells, immediately centrifuged at $1200 \mathrm{~g}$ for $5 \mathrm{~min}$ to allow the association of bacteria with the cellular surface, and incubated for 1, 2, 3, 4 and 8 days. At the end of infection period, gentamicin sulfate (Sigma-Aldrich) $(100 \mu \mathrm{g} / \mathrm{mL})$ was added to the medium for $2 \mathrm{~h}$ to kill all extracellular bacteria - this assay was performed in triplicate, and control wells were left 
uninfected. Cells were then washed extensively and lysed by the addition of $200 \mu \mathrm{L}$ of distilled water for $5 \mathrm{~min}$ and sonicated for $1.30 \mathrm{~min}$. Lysates were serially diluted, plated on Columbia blood agar, and CFUs were counted after 1 week of incubation. To determine intracellular survival after $96 \mathrm{~h}$ of infection, extracellular bacteria were killed by gentamicin treatment for $2 \mathrm{~h}$. Cells were further incubated in normal medium for the remaining time of the indicated infection period. When indicated, cells were pretreated for $6 \mathrm{~h}$ with the specific inhibitors gefitinib (10 $\mu \mathrm{M})$ and GSK583 (1 $\mu \mathrm{M})$ or with a specific antibody against EGFR or its corresponding isotype control antibody at 10 $\mu \mathrm{g} / \mathrm{ml}$. GPA was performed as described above after 1 or 2 days. In some experiments, HUVECs were cultured in the presence of CM from untreated and infected MSCs.

Immunostaining. MSCs $\left(1 \times 10^{4}\right)$ were seeded on coverslips and infected with $B$. henselae at a MOI of 100. Cells were fixed in methanol and sequentially incubated with blocking solution (0.1\% BSA in PBS) for 15 min, rabbit poly anti-B henselae monoclonal antibody (1:50) for $1 \mathrm{~h}$ and biotinylated secondary IgG antibodies for $30 \mathrm{~min}$. Samples were then stained with horseradish peroxidase streptavidin (HRP Streptavidin) or with the chromogen DAB (3, 3'-diaminobenzidine) (ThermoFisher Scientific).

For immunofluorescence analysis, MSCs were seeded at $0.25 \times 10^{4}$ on coverslips, infected with B. henselae (MOI 100), fixed in 3.75\% PBS-buffered paraformaldehyde (PFA), and permeabilized with $0.25 \%$ saponin, $5 \%$ normal goat serum, and $2 \%$ serum bovine albumin in $1 \mathrm{X}$ PBS. Cells were then stained with the indicated antibodies in the presence of $0.25 \%$ saponin.

Cells were analyzed under a Zeiss Observer.Z1 epifluorescence microscope equipped with a Plan-Apochromat 100×/1.4 NA oil objective and ApoTome2 imaging system for optical sectioning. Z-stack images were elaborated through AxioVision 3D and Extended Focus modules.

Immunoblotting. Total cell lysates were prepared in cold lysis buffer (1\% Triton X-100, $1 \%$ NP-40 in PBS, pH 7.4) containing a cocktail of protease and phosphatase inhibitors (SigmaAldrich). Samples (10-20 $\mu \mathrm{g})$ were analyzed by $10 \%$ SDS-PAGE under denaturing conditions, followed by Western blotting, using the indicated antibodies. Chemiluminescent signal (Clarity 
Western ECL Substrate, Bio-Rad) was acquired by ChemiDoc ${ }^{\mathrm{TM}}$ Imaging System (BioRad).

Real-time PCR. Total MSC RNA isolated with the Qiagen RNeasy mini kit was treated with DNase I (Qiagen, Hilden, Germany) and retrotranscribed into cDNA by iScript cDNA Synthesis Kit (Bio-Rad Laboratories Inc., Hercules, CA, USA). Gene specific primers were:

TLR-2 (sense, 5'- CTCATTGTGCCCATTGCTCTT $\quad-3$ '; antisense, 5'TCCAGTGCTTCAACCCACAAC -3'), TLR-4 (sense, 5'- GGCCATTGCTGCCAACAT -3'; antisense, 5'- $\quad$ CAACAATCACCTTTCGGCTTTT $\quad-3^{\prime}$ ), $\quad$ Bax (sense, 5'AGAGGATGATTGCCGCCGT -3'; antisense, 5'- CAACCACCCTGGTCTTGGATC -3'), Bcl-2 (sense, $\quad 5^{\prime}-\quad$ TGCA.CCTGACGCCCTTCAC $\quad-3^{\prime} ; \quad$ antisense, $\quad 5^{\prime}-$ AGACAGCCAGGAGAAATCAAACAG -3'), HPRT (sense, 5'TGACCTTGATTTATTTTGCATACC -3'; antisense, 5'- CGCTTTCCATGTGTGAGGTGATG 3'), RPL13A (sense, 5'-CATAGGAAGCTGGGAGCAAG-3'; antisense, 5'GCCCTCCAATCAGTCTTCTG-3'). For EGFR, NOD1 and NOD2, validated primers from BioRad were used (Unique Assay ID qHsaCID0007564, qHsaCED0005079 and qHsaCED0056944 respectively). For quantitative real-time PCR, the iQTM SYBR Green Supermix (Bio-Rad Laboratories Inc., Segrate, MI, Italy) was used according to the manufacturer's instructions. Reactions were run in duplicate on a CFX96 Real Time System and analyzed by BioRad CFX Maestro Software (Bio-Rad Laboratories Inc.). Gene expression was normalized to HPRT or RPL13A mRNA content.

MTT assay. MSC cell viability was measured by MTT 3-(4,5-dimethylthiazol-2-yl)-2,5diphenyltetrazolium bromide assay. Cells were seeded at a density of $2 \times 10^{3} /$ well in 96 -well plates. After $24 \mathrm{~h}$ of incubation in RPMI 10\% FBS without antibiotics, cells were infected with $B$. henselae (MOI 100). The medium was changed after 4 days to wash out all extracellular bacteria. When indicated, cells were treated with heat-killed $B$. henselae. Cells were then incubated for $3 \mathrm{~h}$ with 20 $\mu 1$ MTT (final concentration $0,5 \mathrm{mg} / \mathrm{ml}$ ). Formazan crystals were solubilized for $10 \mathrm{~min}$ in $100 \mu \mathrm{l}$ DMSO, and OD $570 \mathrm{~nm}$ was measured using a microplate reader (VICTOR3 ${ }^{\mathrm{TM}}$, PerkinElmer, MA, 
USA).

Annexin V Assay. MSCs untreated or infected for $96 \mathrm{~h}$ with $B$. henselae were stained with annexin V-FITC and PI (Sigma Aldrich) according to the manufacturer's instructions. Samples were analyzed by FACS Calibur (Becton Dickinson), and results were quantified using FlowLogic (Miltenyi Biotec, Bergisch Gladbach, Germany).

Flow cytometry. MSCs were collected at the indicated times after infection and preincubated for $30 \mathrm{~min}$ at $4{ }^{\circ} \mathrm{C}$ in $1 \mathrm{X}$ PBS supplemented with $2 \%$ goat serum and $0.2 \%$ sodium azide, washed twice with $1 \%$ bovine serum albumin (BSA). Successively, cells were incubated for 30 min at $4^{\circ} \mathrm{C}$ with anti-human TLR-2 FITC, anti-human TLR-4 PE or control isotypes. Flow cytometry analysis was performed using FACS Calibur and FlowLogic as described above.

Cytokine measurements. MSCs seeded in 24-well plates were infected with a MOI of 100 for the indicated times. For some experiments, cells were pretreated with the pharmacological inhibitors gefitinib and GSK583 or the neutralizing antibody anti-TLR2. Cell-free supernatants were then harvested to measure human VEGF-A, CXCL8, IL-6 and CCL5 production by ELISA (R\&D Systems, Minneapolis, MN, USA). To quantify human PDGF-D, a specific kit from Elabscience (Wuhan, Hubei, P.R.C) was employed.

Preparation of conditioned medium. MSCs, cultured into 12-well plates at a density of $0.5 \times 10^{5}$ cells/well in RPMI 10\% FBS without antibiotics, were left untreated or infected for $96 \mathrm{~h}$ with $B$. henselae. Cells were then extensively washed to remove extracellular bacteria, and fresh RPMI was replaced for $72 \mathrm{~h}$. Conditioned medium was collected, centrifuged at $4000 \mathrm{rpmi}$ for 10 min and then filtered, aliquoted, and stored at $-20^{\circ} \mathrm{C}$.

Angiogenesis array. The human angiogenesis array (Proteome Profiler ${ }^{\mathrm{TM}}$ Array; R\&D Systems) was used to assess the expression of 55 angiogenic-related proteins in MSCs uninfected or infected with $B$. henselae for $96 \mathrm{~h}$. The array membranes were probed with pooled supernatants derived from three independent experiments. Enhanced chemiluminescence was used to detect protein binding to the antibody array, followed by exposure to an X-ray film. The signal intensity of 
each antigen-specific antibody spot was quantified using Fiji-ImageJ (NIH) software. For comparison of the relative expression of proteins in uninfected $v s$ infected cells, the mean pixel density of the pair of duplicate spots for each protein, after subtraction of the mean pixel density of the negative control spots of the respective array, was normalized to the mean pixel density of the positive control spots. Heat map analysis using the normalized data was performed by GraphPad PRISM 8.0 software.

Sprouting assay. Sprouting of HUVEC spheroids was assessed as described previously [25]. Briefly, spheroids were prepared in $20 \%$ methylcellulose medium, embedded in a fibrin gel and stimulated with recombinant human VEGF-A $(30 \mathrm{ng} / \mathrm{mL})$ or with different concentrations of CM from uninfected or infected MSCs. The number of radially growing cell sprouts was counted after $24 \mathrm{~h}$ using an Axiovert 200M microscope equipped with LD A Plan 20X/0.30PH1 objective (Carl Zeiss) and expressed as relative increase over untreated spheroids.

Motility assay. HUVEC motility assay was based on "scratch" wounding of a confluent monolayer. Briefly, HUVECs $\left(1 \times 10^{5}\right)$ were seeded onto $0.1 \%$ collagen type I (BD Biosciences, Italy)-coated six-well plates in complete medium until a confluent monolayer was formed. The cell monolayers were scratched using a pipette tip, washed with 1X PBS to remove the undetached cells and treated with MSC conditioned medium. After $24 \mathrm{~h}$, cells were photographed under an Axiovert 200M microscope (Carl Zeiss) equipped with LD A Plan 20X/0.30PH1. The healed area was quantified through computerized analysis by subtracting the wound area at $24 \mathrm{~h}$ from the initial area.

Tube formation assay. EC vessel formation was assessed by tube morphogenesis assay in a three-dimensional (3D) collagen matrix. To this end, HUVECs were seeded onto Reduced Growth Factor Basement Membrane Matrix Cultrex ${ }^{\circledR}$ (BME) (Trevigen, Italy)-coated $\mu$-slide angiogenesis chamber (Ibidi, Martinsried, Germany) at a density of $4.0 \times 10^{4}$ cells $/ \mathrm{cm}^{2}$ in the absence or presence of CM from untreated or infected MSCs. After $48 \mathrm{~h}$, cells were photographed using an Axiovert 
200M microscope, and the number of meshes/field was counted.

Statistical Analysis. Statistical significance was determined by non-parametric Student's ttest and one-way analysis of variance followed by Tukey's multiple-comparison test. Results were analyzed by GraphPad PRISM 8.0 software (CA, USA).

\section{RESULTS}

B. henselae invades and persists in MSCs. To characterize the interaction of MSCs with B. henselae, adipose-derived MSCs were infected with MOI of 100:1 for 1, 2, 3, 4 and 8 days and then treated with gentamicin to kill all residual extracellular bacteria. Subsequently, the number of viable intracellular bacteria was measured by colony-forming unit (CFU) assay. The number of $B$. henselae invading MSCs increased progressively over a 3-day period and the number of CFUs in MSCs remained unchanged up to 8 days $(P<0.05)$ (Fig. 1A). At day 8 post-infection (pi), the vast majority of MSCs contained $B$. henselae, as demonstrated by the strong cytoplasmic reactivity of an anti-B. henselae monoclonal antibody (anti-BH) (Fig. 1B). As expected, at lower MOIs, we observed a reduction in the number of viable intracellular bacteria. At a MOI 10:1 after 1 day of infection, about 30 bacteria per 100 cells were detected (data not shown). To obtain a sufficient number of intracellular bacteria for proper readout, subsequent studies were thus carried out at an MOI of 100.

To assess $B$. henselae intracellular survival after the initial infection and gentamicin treatment, MSCs were cultured in medium without gentamicin for four additional days. The number of viable intracellular bacteria recovered, which remained stable during the first $96 \mathrm{~h}$, was significantly lower at day 8 compared to day 4 (Fig. 1C). The ability of $B$. henselae to invade MSCs was further assessed by comparing its infection efficiency in MSCs vs HUVECs, a known target of B. henselae infection. The number of intracellular bacteria recovered after $24 \mathrm{~h}$ of infection from MSCs was significantly higher than that recovered from HUVECs (Fig. 1D). 
Next, we followed MSC infection by fluorescence microscopy. At day 1 pi, B. henselaestained with DAPI (Cyan)—remained mainly anchored to the MSC membrane, with only a few bacteria present in the cytoplasm (Fig. 2A, upper right panel, arrowhead). From day 2 pi onward, the number of internalized bacteria increased, and a significant amount of $B$. henselae localized in perinuclear vesicles (Fig. 2A, lower left and central panel, thin arrows). After 8 days pi, the bacteria aggregated and co-localized with F-actin in globular structures called invasomes, first described in Bartonella-infected ECs (Fig. 2A, lower right panel, large arrow; and Fig. 2B) as attested by 3D immunofluorescence analysis. By contrast, from day 2 to day 8 , a significant amount of bacteria entered individually or in the form of small aggregates, leading to the formation of Bartonella-containing vacuoles (BCVs), mainly localized in the perinuclear compartment.

Altogether, these findings indicate that B. henselae is internalized by MSCs-even more efficiently than HUVECs - where it can persist for a prolonged time in a quiescent state.

B. henselae infection enhances MSC proliferation. We next asked whether B. henselae infection would affect MSC survival. B. henselae infection did not induce cell death in MSCs as demonstrated by similar amounts of Annexin V positive cells found in uninfected $v$ infected MSCs (Fig. 3A). This finding was further supported by the unaltered Bcl-2 (antiapoptotic) /Bax (apoptotic) expression ratio observed in these cells (Fig. 3B). We then assessed the effect of infection on the proliferation rate of MSCs. Infected-MSCs grew significantly faster compared to their uninfected counterparts. Conversely, heat-inactivated B. henselae (HKB.h.) failed to enhance MSC proliferation (Fig. 3C).

Role of TLR2, EGFR and NOD1 in MSC infection with B. henselae. As TLR, NOD and EGFR are involved in pathogen/host cell interactions [26], we next assessed the expression of these receptors in response to $B$. henselae infection. Interestingly, $B$. henselae infection led to a more than 6-fold increase in TLR2 expression at both mRNA and protein level, while TLR4 expression remained basically unchanged (Fig. 4A and 4B). Furthermore, RT-PCR analysis showed a 
significant upregulation of NOD1 mRNA at day 2 and 4 pi (Fig. 4A). NOD2 gene expression was not detected in uninfected or infected MSCs. Lastly, B. henselae infection significantly increased EGFR mRNA and phosphorylation levels (Fig. 4A and 4C, respectively). Specifically, we detected increased phosphorylation as early as $30 \mathrm{~min}$ pi, which remained above basal levels up to $120 \mathrm{~min}$ pi (Figure 4C).

The involvement of these receptors was evaluated in the production of CXCL8, a cytokine shown to be triggered by Bartonella in different cell types [27], Bartonella infection of MSCs enhanced their ability to produce CXCL8, which was neutralized by incubation with an anti-TLR2 neutralizing antibody (Fig. 4D). Similarly, treatment with the EGFR inhibitor gefitinib or with the selective RIP2K inhibitor GSK583 significantly reduced the release of CXCL8 in B. henselaeinfected MSCs (Fig. 4D), suggesting that the EGFR/NOD pathway may play a role in CXCL8 transcriptional regulation. Finally, to address the role of bacterium-activated EGFR in Bartonella entry, we treated MSCs with the EGFR inhibitor gefitinib and a neutralizing anti-EGFR antibody, detecting a reduced bacterial internalization by about $70 \%$ and $50 \%$, respectively, compared to untreated cells (Fig. 4E).

\section{B. henselae-infected MSCs promote angiogenesis and infection of endothelial cells.}

Since MSCs regulate vascular remodeling and angiogenesis [28], we assessed the pro-angiogenic activity of conditioned medium (CM) from B. henselae-infected MSCs. To this end, CM from uninfected or B. henselae-infected MSC cultures were tested in a scratch wound healing assay using HUVECs. CM from B. henselae-infected MSCs (CM-MSC B. henselae), induced a more rapid repair of HUVECs monolayer (Fig. 5A). In addition, the CM-MSC B. henselae was 9 fold more powerful then CM of uninfected MCS (CM-MSC CTRL) on a spheroid-based sprouting assay, which faithfully recapitulate the proliferation, invasion and reorganization in tube-like structure of ECs (Fig. 5B). In keeping with the pro-angiogenic activity of MSCs, the CM-MSC CTRL induced the formation of radial sprouts, similarly to what induced by spheroids stimulation with $30 \mathrm{ng} / \mathrm{mL}$ of VEGF-A (Fig. 5B, right panel). Importantly, CM-MSC B. henselae but not that from uninfected 
cells (CM-MSC CTRL) accelerated the morphogenesis of HUVECs when seeded on Cultrex Extracellular Matrix, as judged by the number of closed structures formed at $18 \mathrm{~h}$ pi (Fig. 5C).

Even though ECs and MSCs can crosstalk through soluble mediators [29], there is no data on the effects of MSC on the susceptibility of ECs to bacterial infection. We thus assessed the extent of Bartonella internalization, at day 1 pi, in HUVECs pretreated with CM from uninfected MSCs or B. henselae-infected MSCs. While there were no differences in the yield of bacteria between control HUVECs (Ctrl) and HUVECs pretreated with CM-MSC CTRL, a significantly higher number of bacteria was detected in HUVECs pretreated with CM-MSC B. henselae (Fig. 5D).

Angiogenic expression profile of $\boldsymbol{B}$. henselae-infected MSCs. Finally, we assessed the impact of $B$. henselae infection on the ability of MSCs to modulate the expression of proinflammatory and pro-angiogenetic molecules. For this purpose, we probed an antibody angiogenesis array with CM from uninfected and 4-day-infected MSCs. Among the 55 proteins of the assay, 27 were detected in CM of both uninfected and infected MSCs. Densitometric analysis showed the upregulation of FGF-7, CXCL8, MMP-9, PIGF, Serpin E1, TSP-1, uPA and VEGF, in B. henselae-infected MSCs CM compared to those from uninfected MSCs (Fig. 6A). Intriguingly, activin A was the only growth factor downregulated in B. henselae-infected MSCs (Fig. 6A). Of note MCP-1, PTX3 and TIMP-1 were all highly expressed but remained unchanged following infection (Fig. 6A, 6B and Suppl. Fig. S1, Additional File 1). The quantification by ELISA of the increased production of CXCL8 and VEGF in the supernatants of MSCs infected for 1, 4 and 7 days was in good agreement with the array data (Fig. 6C). Finally, other molecular factors known for their angiogenic activity, but not included in our array, such as IL-6, CCL5 and PDGF-D, were also induced following B. henselae infection (Fig. 6C).

\section{DISCUSSION}

Bartonella spp exploits several mechanisms to hide inside erythrocytes and endothelial cells (ECs) to evade immune responses and persist in both animal reservoir and human host. Numerous 
evidence indicate that the blood-stage phase is preceded by the infection of cellular niches that periodically release bacteria able to invade erythrocytes. ECs were the first cell types considered a primary niche as they support Bartonella replication and reside in proximity to the bloodstream [2,30]. However, later studies identified additional Bartonella persistence sites including hematopoietic progenitor cells and dendritic cells [8,31].

In this study we provide evidence showing that once inside $B$. henselae resides in MSCs without proliferating for several days. Bartonella localizes in numerous perinuclear membrane bound vacuoles, as previously shown in HUVECs and MonoMac cells [32,33], or at late time points of infection, as aggregated bacteria enclosed into $\mathrm{F}$ actin-rich cell membrane protrusions identified as invasome structures [34].

MSCs sense microorganisms trough the expression of various PRR including Toll-like receptors (TLRs) and Nod-like receptors (NLRs). The engagement of such receptors modulate MSC functions and their abilities to secrete cytokines [35]. Our studies revealed that TLR2, NOD1 and EGFR are involved in the recognition and responses to Bartonella by MSCs. We show that, upon infection with $B$. henselae, MSCs secret large amounts of CXCL8, which is curbed by incubation with an anti-TLR2 antibody. A central role of TLR2 signaling during Bartonella infection is consistent with previous findings indicating that $B$. henselae, despite being Gram-negative, preferentially activates TLR2 [31]. In infected cells, NOD1 and NOD2 recognize bacterial peptidoglycan derivatives released into the cytosol and, upon ligand association with the adaptor protein receptor-interacting-serine/threonine-protein kinase 2 (RIPK2 or RIP2), trigger proinflammatory signaling [36]. In our experimental system, inhibition of the RIP2 with the highly RIPK2-specific compound GSK583[37] decreased CXCL8 release, indicating that NOD1 activation and signaling through RIP2 during MSC infection is, in part, responsible for inducing the inflammatory response to $B$. henselae infection. Consistent with our results, NOD1 mediates CXCL8 induction after recognition of Helicobacter pylori, Escherichia coli $[38,39]$ and Chlamydia pneumoniae [40]. Importantly, we also show that gefitinib, an inhibitor of EGFR tyrosine kinase 
domain, used to treat various forms of cancer, can hamper $B$. henselae-mediated induction of CXCL8, suggesting a role of EGFR in this pathway. Gefitinib also exerts an off-target inhibitory activity on the expression of RIP2 [41], thus the inhibition of CXCL8 secretion may be due to blockage of NOD/RIP2 signaling alongside that of EGFR. In support to this hypothesis, EGFR/NOD cooperation has been recently involved in cytokine production in dengue virus infected monocytes [42]. Moreover, a growing body of literature highlights the importance of EGFR/ErbB in several bacterial and viral inflammatory responses [15,43] and in pathogenic angiogenesis [44]. In addition to stimulation of EGFR tyrosine kinase phosphorylation, Bartonella also enhanced EGFR mRNA expression suggesting that this upregulation could serve as a positive feedback system. A functional role of EGFR signaling in the immune response against $B$. henselae is further supported by the observation that treatment of MSCs with the kinase inhibitor gefitinib or an antiEGFR antibody significantly decreases Bartonella internalization. In this regard, EGFR has been recently shown to act as a cofactor in mediating pathogen internalization in host cells (e.g., HBV, HCV, Chlamydia and Candida) [15]. Our finding indicates an important role of EGFR activation in Bartonella invasion; however, as these EGFR inhibitors do not completely abrogate Bartonella uptake by MSCs, it is likely that other receptors, other than EGFR, may play a role in Bartonella infection. Moreover, it remains to be investigated whether EGFR activation is due to the direct interaction of Bartonella with the EGFR extracellular domain or by its transactivation by EGFR ligands (i.e., EGF, HBEGF, TGFa, BTC, AREG, EREG and EPGN) [42] as shown for H. pylori and Neisseria spp. [45,46]. EGFR signaling pathways exert an antiapoptotic activity in Pseudomonas- and Helycobacter- infected cells [47,48] suggesting that EGFR activation by Bartonella promotes the survival and proliferation of infected MSCs.

These effects may also be explained at least in part by the robust release of cytokine/growth factors caused by Bartonella infection. In addition to CXCL8, angiogenic factors upregulated in infected MSCs include FGF-7, MMP-9, PIGF, serpin E1, TSP-1, uPA, IL-6, CCL5 and VEGF, leading to the induction of a pro-angiogenic phenotype in ECs as well as an increased susceptibility 
of ECs to infection. Data reporting a role of MSCs in facilitating the infection of other cell types are sparse and concern mainly phagocytic cells. MSCs enhance bacterial uptake by PMNs, resulting in enhanced clearance of bacteria [49], and mediate the reactivation of HIV in monocytic cells [50]. The secretion of factors by infected MSCs, acting in a paracrine fashion, may stimulate the infection of ECs allowing bacterial persistence. Consistent with the fact that ECs are not the major cell type producing VEGF [32] Bartonella-triggered angiogenesis has been shown to be supported by VEGF and CXCL8 released by macrophages infiltrating the lesions [8]. Since MSCs are recruited at the sites of infection/inflammation, just in contact with ECs [29,51], we propose that infected MSCs might support the angiogenic loop by releasing high levels of pro-angiogenic factors. A role of MSCs can be envisioned in different scenarios of Bartonella infections. MSC are recruited around the granuloma of lymph node tuberculosis to establish a persistent infection and likely to suppress $\mathrm{T}$ cell response [52]. Moreover, MSC have been also found in oral pyogenic granuloma tissues [53]. Granulomatous lymphadenitis is the pathological hallmark of cat scratch disease whereby MSCs could also be hired in Bartonella granuloma to contribute to the immune pathogenesis. The crosstalk between MSCs and ECs is well characterize in the bone marrow where and erythroid differentiation of $\mathrm{CD} 4^{+}$stem cells [55]. As B. henselae can infect $\mathrm{CD} 34^{+}$bone marrow progenitor cells, bone marrow has been proposed as one of the potential niches. Moreover multifocal bone marrow involvement has been shown in CSD [56,57] and a contribution of $B$. henselae infection to ineffective erythropoiesis has been suggested [58]. Bartonella-infected MSCs releasing soluble molecules can recruit and activate ECs which in turn collaborate with MSCs in the fine regulation of the hematopoietic stem cell niche.

\section{CONCLUSIONS}

In conclusion, this study provides novel insights into the role of MSCs in serving as a bacterial reservoir during $B$. henselae infection and identifies TLR2, NOD1 and EGFR as the 
receptors involved in the recognition of $B$. henselae. Moreover, $B$. henselae triggers a potent 440 proangiogenic effect, which activates ECs and at the same time enhances their susceptibility to 441 bacterial infection. Thus, a better understanding of the involvement of MSCs in Bartonella-induced 442 angiogenesis will allow the development of targeted therapeutic strategies for the treatment of 443 vascular proliferative disorders.

446 Abbreviations

447 MSCs: mesenchymal stromal cells

$448 \quad$ ECs: endothelial cells

449 DCs: dendritic cells

450 TLRs: Toll-like receptors

451 NLRs: NOD-like receptors

452 PRRs: Pattern Recognition Receptors

453 CSD: cat scratch disease

454 BA: bacillary angiomatosis

455 BP: bacillary peliosis

456 GPA: gentamicin protection assay

457 CM: conditioned medium

458 MOI: multiplicity of infection

459 ANOVA: analysis of variance

\section{REFERENCES}

462 1. Florin TA, Zaoutis TE, Zaoutis LB. Beyond Cat Scratch Disease: Widening Spectrum of 463 Bartonella henselae Infection. Pediatrics. American Academy of Pediatrics; 2008;121:e1413-25.

464 2. Harms A, Dehio C. Intruders below the Radar: Molecular Pathogenesis of Bartonella spp. Clin 465 Microbiol Rev. 2012;25:42-78. 
3. McCord AM, Burgess AWO, Whaley MJ, Anderson BE. Interaction of Bartonella henselae with Endothelial Cells Promotes Monocyte/Macrophage Chemoattractant Protein 1 Gene Expression and Protein Production and Triggers Monocyte Migration. Infect Immun. 2005;73:5735-42.

4. Berrich M, Kieda C, Grillon C, Monteil M, Lamerant N, Gavard J, et al. Differential Effects of Bartonella henselae on Human and Feline Macro- and Micro-Vascular Endothelial Cells. Bruggemann H, editor. PLoS ONE. 2011;6:e20204.

5. Tsukamoto K, Shinzawa N, Kawai A, Suzuki M, Kidoya H, Takakura N, et al. The Bartonella autotransporter BafA activates the host VEGF pathway to drive angiogenesis. Nat Commun. 2020;11:3571.

6. Musso T, Badolato R, Ravarino D, Stornello S, Panzanelli P, Merlino C, et al. Interaction of Bartonella henselae with the Murine Macrophage Cell Line J774: Infection and Proinflammatory Response. Clements JD, editor. Infect Immun. 2001;69:5974-80.

7. Resto-Ruiz SI, Schmiederer M, Sweger D, Newton C, Klein TW, Friedman H, et al. Induction of a Potential Paracrine Angiogenic Loop between Human THP-1 Macrophages and Human Microvascular Endothelial Cells during Bartonella henselae Infection. Infect Immun. 2002;70:4564-70.

8. Mändle T, Einsele H, Schaller M, Neumann D, Vogel W, Autenrieth IB, et al. Infection of human CD34+ progenitor cells with Bartonella henselae results in intraerythrocytic presence of B henselae. Blood. 2005;106:1215-22.

9. Pittenger MF, Discher DE, Péault BM, Phinney DG, Hare JM, Caplan AI. Mesenchymal stem cell perspective: cell biology to clinical progress. Npj Regen Med. 2019;4:22.

10. Melchiorri AJ, Nguyen B-NB, Fisher JP. Mesenchymal Stem Cells: Roles and Relationships in Vascularization. Tissue Eng Part B Rev. 2014;20:218-28.

11. Di Somma M, Schaafsma W, Grillo E, Vliora M, Dakou E, Corsini M, et al. Natural HistogelBased Bio-Scaffolds for Sustaining Angiogenesis in Beige Adipose Tissue. Cells. 2019;8:1457.

12. Alcayaga-Miranda F, Cuenca J, Khoury M. Antimicrobial Activity of Mesenchymal Stem Cells: Current Status and New Perspectives of Antimicrobial Peptide-Based Therapies. Front Immunol [Internet]. 2017 [cited 2020 Sep 9];8. Available from: http://journal.frontiersin.org/article/10.3389/fimmu.2017.00339/full

13. Bessède E, Dubus P, Mégraud F, Varon C. Helicobacter pylori infection and stem cells at the origin of gastric cancer. Oncogene. Nature Publishing Group; 2015;34:2547-55.

14. De Luca A, Gallo M, Aldinucci D, Ribatti D, Lamura L, D'Alessio A, et al. Role of the EGFR ligand/receptor system in the secretion of angiogenic factors in mesenchymal stem cells. J Cell Physiol. 2011;226:2131-8.

15. Ho J, Moyes DL, Tavassoli M, Naglik JR. The Role of ErbB Receptors in Infection. Trends Microbiol. 2017;25:942-52.

16. Krasnodembskaya A, Song Y, Fang X, Gupta N, Serikov V, Lee J-W, et al. Antibacterial Effect of Human Mesenchymal Stem Cells Is Mediated in Part from Secretion of the Antimicrobial Peptide LL-37. STEM CELLS. 2010;28:2229-38. 
17. Meisel R, Brockers S, Heseler K, Degistirici Ö, Bülle H, Woite C, et al. Human but not murine multipotent mesenchymal stromal cells exhibit broad-spectrum antimicrobial effector function mediated by indoleamine 2,3-dioxygenase. Leukemia. 2011;25:648-54.

18. Gonzalez-Rey E, Anderson P, Gonzalez MA, Rico L, Buscher D, Delgado M. Human adult stem cells derived from adipose tissue protect against experimental colitis and sepsis. Gut. 2009;58:929-39.

19. Lee N-Y, Ko W-C, Hsueh P-R. Nanoparticles in the Treatment of Infections Caused by Multidrug-Resistant Organisms. Front Pharmacol [Internet]. Frontiers; 2019 [cited 2020 Oct 28];10. Available from: https://www.frontiersin.org/articles/10.3389/fphar.2019.01153/full

20. Sutton MT, Fletcher D, Ghosh SK, Weinberg A, van Heeckeren R, Kaur S, et al. Antimicrobial Properties of Mesenchymal Stem Cells: Therapeutic Potential for Cystic Fibrosis Infection, and Treatment. Stem Cells Int. 2016;2016:1-12.

21. Gupta N, Nizet V. Stabilization of Hypoxia-Inducible Factor-1 Alpha Augments the Therapeutic Capacity of Bone Marrow-Derived Mesenchymal Stem Cells in Experimental Pneumonia. Front Med. 2018;5:131.

22. Das B, Kashino SS, Pulu I, Kalita D, Swami V, Yeger H, et al. CD271+ Bone Marrow Mesenchymal Stem Cells May Provide a Niche for Dormant Mycobacterium tuberculosis. Sci Transl Med. 2013;5:170ra13-170ra13.

23. Fatima S, Kamble SS, Dwivedi VP, Bhattacharya D, Kumar S, Ranganathan A, et al. Mycobacterium tuberculosis programs mesenchymal stem cells to establish dormancy and persistence. J Clin Invest. 2019;130:655-61.

24. Scutera S, Salvi V, Lorenzi L, Piersigilli G, Lonardi S, Alotto D, et al. Adaptive Regulation of Osteopontin Production by Dendritic Cells Through the Bidirectional Interaction With Mesenchymal Stromal Cells. Front Immunol. 2018;9:1207.

25. Rezzola S, Di Somma M, Corsini M, Leali D, Ravelli C, Polli VAB, et al. VEGFR2 activation mediates the pro-angiogenic activity of BMP4. Angiogenesis. 2019;22:521-33.

26. Oviedo-Boyso J, Bravo-Patiño A, Baizabal-Aguirre VM. Collaborative Action of Toll-Like and Nod-Like Receptors as Modulators of the Inflammatory Response to Pathogenic Bacteria. Mediators Inflamm. 2014;2014:1-16.

27. McCord AM, Resto-Ruiz SI, Anderson BE. Autocrine Role for Interleukin-8 in Bartonella henselae-Induced Angiogenesis. Infect Immun. 2006;74:5185-90.

28. Rezaie J, Heidarzadeh M, Hassanpour M, Amini H, Shokrollahi E, Ahmadi M, et al. The Angiogenic Paracrine Potential of Mesenchymal Stem Cells. In: Ahmed Al-Anazi K, editor. Update Mesenchymal Induc Pluripotent Stem Cells [Internet]. IntechOpen; 2020 [cited 2020 Sep 10]. Available from: https://www.intechopen.com/books/update-on-mesenchymal-and-inducedpluripotent-stem-cells/the-angiogenic-paracrine-potential-of-mesenchymal-stem-cells

29. Nassiri SM, Rahbarghazi R. Interactions of Mesenchymal Stem Cells with Endothelial Cells. Stem Cells Dev. Mary Ann Liebert, Inc., publishers; 2013;23:319-32.

30. Dehio C. Bartonella -host-cell interactions and vascular tumour formation. Nat Rev Microbiol. Nature Publishing Group; 2005;3:621-31. 
31. Vermi W. Role of dendritic cell-derived CXCL13 in the pathogenesis of Bartonella henselae Brich granuloma. Blood. 2006;107:454-62.

32. Kempf VAJ, Schaller M, Behrendt S, Volkmann B, Aepfelbacher M, Cakman I, et al. Interaction of Bartonella henselae with endothelial cells results in rapid bacterial rRNA synthesis and replication. Cell Microbiol. 2000;2:431-41.

33. Kempf VAJ, Schairer A, Neumann D, Grassl GA, Lauber K, Lebiedziejewski M, et al. Bartonella henselae inhibits apoptosis in Mono Mac 6 cells: B. henselae inhibits apoptosis in monocytes. Cell Microbiol. 2004;7:91-104.

34. Truttmann MC, Misselwitz B, Huser S, Hardt W-D, Critchley DR, Dehio C. Bartonella henselae engages inside-out and outside-in signaling by integrin $\beta 1$ and talin 1 during invasome-mediated bacterial uptake. J Cell Sci. 2011;124:3591-602.

35. Najar M, Krayem M, Meuleman N, Bron D, Lagneaux L. Mesenchymal Stromal Cells and TollLike Receptor Priming: A Critical Review. Immune Netw. 2017;17:89.

36. Strober W, Murray PJ, Kitani A, Watanabe T. Signalling pathways and molecular interactions of NOD1 and NOD2. Nat Rev Immunol. 2006;6:9-20.

37. Haile PA, Votta BJ, Marquis RW, Bury MJ, Mehlmann JF, Singhaus R, et al. The Identification and Pharmacological Characterization of 6-( tert -Butylsulfonyl)- $N$-(5-fluoro- $1 \mathrm{H}$-indazol-3yl)quinolin-4-amine (GSK583), a Highly Potent and Selective Inhibitor of RIP2 Kinase. J Med Chem. 2016;59:4867-80.

38. Viala J, Chaput C, Boneca IG, Cardona A, Girardin SE, Moran AP, et al. Nod1 responds to peptidoglycan delivered by the Helicobacter pylori cag pathogenicity island. Nat Immunol. 2004;5:1166-74.

39. Kim JG, Lee SJ, Kagnoff MF. Nod1 Is an Essential Signal Transducer in Intestinal Epithelial Cells Infected with Bacteria That Avoid Recognition by Toll-Like Receptors. Infect Immun. 2004;72:1487-95.

40. Opitz B, Förster S, Hocke AC, Maass M, Schmeck B, Hippenstiel S, et al. Nod1-Mediated Endothelial Cell Activation by Chlamydophila pneumoniae. Circ Res. 2005;96:319-26.

41. Tigno-Aranjuez JT, Asara JM, Abbott DW. Inhibition of RIP2's tyrosine kinase activity limits NOD2-driven cytokine responses. Genes Dev. 2010;24:2666-77.

42. Duran A, Valero N, Mosquera J, Fuenmayor E, Alvarez-Mon M. Gefitinib and pyrrolidine dithiocarbamate decrease viral replication and cytokine production in dengue virus infected human monocyte cultures. Life Sci. 2017;191:180-5.

43. Bentz GL, Yurochko AD. Human CMV infection of endothelial cells induces an angiogenic response through viral binding to EGF receptor and $\beta 1$ and $\beta 3$ integrins. Proc Natl Acad Sci. National Academy of Sciences; 2008;105:5531-6.

44. Singh B, Carpenter G, Coffey RJ. EGF receptor ligands: recent advances. F1000Research. 2016;5:2270.

45. Swanson KV, Griffiss JM, Edwards VL, Stein DC, Song W. Neisseria gonorrhoeae-induced transactivation of EGFR enhances gonococcal invasion. Cell Microbiol. 2011;13:1078-90. 
46. Keates S, Keates AC, Katchar K, Peek, Jr. RM, Kelly CP. Helicobacter pylori Induces Up- Regulation of the Epidermal Growth Factor Receptor in AGS Gastric Epithelial Cells. J Infect Dis. 2007;196:95-103.

47. Zhang J, Li H, Wang J, Dong Z, Mian S, Yu F-SX. Role of EGFR Transactivation in Preventing Apoptosis in Pseudomonas aeruginosa-Infected Human Corneal Epithelial Cells. Invest Ophthalmol Vis Sci. 2004;45:2569-76.

48. Yan F, Cao H, Chaturvedi R, Krishna U, Hobbs SS, Dempsey PJ, et al. Epidermal growth factor receptor activation protects gastric epithelial cells from Helicobacter pylori-induced apoptosis. Gastroenterology. 2009;136:1297-307, e1-3.

49. Brandau S, Jakob M, Bruderek K, Bootz F, Giebel B, Radtke S, et al. Mesenchymal Stem Cells Augment the Anti-Bacterial Activity of Neutrophil Granulocytes. PLOS ONE. Public Library of Science; 2014;9:e106903.

50. Chandra PK, Gerlach SL, Wu C, Khurana N, Swientoniewski LT, Abdel-Mageed AB, et al. Mesenchymal stem cells are attracted to latent HIV-1-infected cells and enable virus reactivation via a non-canonical PI3K-NFאB signaling pathway. Sci Rep. 2018;8:14702.

51. Del Prete A, Scutera S, Sozzani S, Musso T. Role of osteopontin in dendritic cell shaping of immune responses. Cytokine Growth Factor Rev. 2019;50:19-28.

52. Raghuvanshi S, Sharma P, Singh S, Van Kaer L, Das G. Mycobacterium tuberculosis evades host immunity by recruiting mesenchymal stem cells. Proc Natl Acad Sci. 2010;107:21653-8.

53. Dehghani Nazhvani A, Ahzan S, Hosseini S-M, Attar A, Monabati A, Tavangar MS. Purification of Stem Cells from Oral Pyogenic Granuloma Tissue. Open Dent J. 2018;12:560-6.

54. Mitroulis I, Kalafati L, Bornhäuser M, Hajishengallis G, Chavakis T. Regulation of the Bone Marrow Niche by Inflammation. Front Immunol [Internet]. Frontiers; 2020 [cited 2020 Nov 19];11. Available from: https://www.frontiersin.org/articles/10.3389/fimmu.2020.01540/full

55. Perucca S, Di Palma A, Piccaluga PP, Gemelli C, Zoratti E, Bassi G, et al. Mesenchymal stromal cells (MSCs) induce ex vivo proliferation and erythroid commitment of cord blood haematopoietic stem cells (CB-CD34+ cells). PloS One. 2017;12:e0172430.

56. Hipp SJ, O??Shields A, Fordham LA, Blatt J, Hamrick HJ, Henderson FW. Multifocal Bone Marrow Involvement in Cat-Scratch Disease: Pediatr Infect Dis J. 2005;24:472-4.

57. Donà D, Nai Fovino L, Mozzo E, Cabrelle G, Bordin G, Lundin R, et al. Osteomyelitis in CatScratch Disease: A Never-Ending Dilemma-A Case Report and Literature Review. Case Rep Pediatr. 2018;2018:1-8.

58. Randell MG, Balakrishnan N, Gunn- Christie R, Mackin A, Breitschwerdt EB. Bartonella henselae infection in a dog with recalcitrant ineffective erythropoiesis. Vet Clin Pathol. 2018;47:45-50. 
623 This study was carried out in accordance with the recommendations of "Comitato Etico

624 Interaziendale A.O.U. Città della Salute e della Scienza di Torino-A.O. Ordine Mauriziano-ASL

625 TO1, number 0009806" with written informed consent from all subjects. All subjects gave written 626 informed consent in accordance with the Declaration of Helsinki. The protocol was approved by the 627 “Comitato Etico Interaziendale A.O.U. Città della Salute e della Scienza di Torino-A.O. Ordine 628 Mauriziano-ASL TO1."

\section{Availability of data and materials}

630 All data and materials are available upon request.

\section{Author Contributions}

$632 \mathrm{SaS}, \mathrm{SM}, \mathrm{SiS}$, and TM participated in the design of the study.

633 SaS, RS, GP, EG, MB, VS, DA, and TS participated in data acquisition and analysis.

634 TM, SM and SaS wrote the manuscript.

635 SiS participated in data interpretation and manuscript revision.

\section{Conflict of Interest Statement}

637 The authors declare that the research was conducted in the absence of any commercial or financial 638 relationships that could be construed as a potential conflict of interest.

\section{Acknowledgments}

640 The authors thank Prof William Vermi, Department of Molecular and Translational Medicine, 641 University of Brescia, for immunohistochemistry analysis of the MSC/B. henselae interaction.

\section{$642 \quad$ Funding}

643 This work was supported by funds from the Compagnia di San Paolo, Fondazione Ricerca 644 Molinette, AIRC (Associazione Italiana Ricerca sul Cancro) project IG15811 (2015-2017) and 645 project IG 20776 (2017). 
FIGURE LEGENDS

650

651

FIG 1. B. henselae invades and persists in MSCs. (A) Invasion rates of B. henselae into MSCs

652

653

654

655

656

657

658

659

660

661

662

663

664

665

666

667

668

669

670

671

were measured at day 1, 2, 3, 4 and 8 pi by gentamicin protection assay (GPA). After infection, cells were treated with gentamicin, and the number of intracellular bacteria was determined by CFU count. Data are expressed as means \pm SEM from two independent experiments carried out in triplicate $\left(* P<0.05\right.$ vs $\log _{10} \mathrm{CFU}$ at $1 \mathrm{~d}$; unpaired t-test). (B) Uninfected (CTRL) or B. henselaeinfected MSCs (8 days) were immunostained with an anti- $B H$ antibody and counterstained with hematoxylin (upper panel 20X, lower panel 40X). (C) To determine intracellular survival after 4 days of infection, extracellular bacteria were killed by gentamicin treatment and incubated in normal medium for the indicated times. Mean values \pm SEM of triplicate samples are representative of three independent experiments. $\left({ }^{*} P<0.05\right.$; unpaired t-test). (D) Invasion rates of $B$. henselae in MSCs or HUVECs $\left(60,000\right.$ cells each, respectively). The number of intracellular bacteria as $\log _{10}$ CFU was quantified at 1 day pi ( $* P<0.05$ MSCs $v s$ HUVECs; unpaired t-test).

FIG 2. B. henselae localizes in invasome structures in MSCs. (A) Immunofluorescence of $B$. henselae-infected MSCs at 1, 2, 4 and 8 days pi and uninfected control MSCs (CTLR). B. henselae and cell membranes were stained with DAPI (cyan) and wheat germ agglutinin-Alexa Fluor 594 (red), respectively, and analyzed with an epifluorescence microscope. Bacteria anchored to the MSC membrane are indicated with arrowheads. The thin arrows ( 2 and 4 days) indicate internalized bacteria within membrane bound compartments in the perinuclear area, whereas the large arrows $(8$ days) highlight sizeable intracellular bacterial aggregates called invasomes. Each image also shows the basal portion of adherent MSC cells, with the orthogonal z reconstruction of the whole cell.

Representative image of an invasome. MSCs were infected with B. henselae for 8 days and then 
washed and fixed with PFA. Samples were stained for F-actin (red), wheat germ agglutinin (WGA) (green) and DAPI and analyzed as described in panel A (bar: $10 \mu \mathrm{m})$.

FIG 3. B. henselae favors the proliferation of infected MSCs. (A) MSC death was evaluated by FACS analysis after 4 days of infection with B. henselae. Uninfected MSCs (left panel; CTRL) and infected MSCs (right panel; B. henselae) were double-stained with FITC-annexin V and PI. Counterstaining with PI allowed differentiation of necrotic cells (upper left quadrant of the dot plot), late apoptotic cells (upper right quadrant) and early apoptotic cells (lower right quadrant). The percentages of cells localizing to these quadrants are indicated in each quadrant. Data are representative of 3independent experiments. (B) The Bcl-2/Bax expression ratio was analyzed in control and B. henselae-infected MSCs at 2 days pi by qPCR. Gene expression was normalized to HPRT. Data are expressed as means \pm SEM of 4 independent experiments (ns not significant; unpaired t-test). (C) Proliferation assay. MSCs were treated as indicated for 0, 2, 4, and 8 days and analyzed by MTT assay. Untreated MSCs (white circle); B. henselae infected MSC (black circle); and heat killed B. henselae-treated MSCs (HKB.h.) (grey circle). Data are expressed as means \pm SEM of triplicate samples of one experiment representative of 3 independent ones $(* P<0.05 B$. henselae vs CTRL, unpaired t-test).

FIG 4. Expression of TLR2, NOD1 and EGFR in B. henselae-infected MSCs. (A) mRNA expression levels of TLR2, TLR4, NOD1 and EGFR in uninfected (white bar) and B. henselaeinfected MSCs (black bar) were determined by qPCR and normalized to RPL13A. Data are expressed as means \pm SEM of four independent experiments ( $* P<0.05$; unpaired t-test). (B) TLR2 and TLR4 protein expression levels on MSC membranes were analyzed by FACS in MSCs at $4 \mathrm{~d}$ pi. Cells were immunostained with anti-TLR2, anti-TLR4 or specific isotype control antibodies. The percentages of positive cells are indicated in each quadrant. Fluorescence minus one (FMO) controls for the antibodies are shown as well. Data are representative of three independent experiments. (C) Cell extracts from MSCs infected with B. henselae for 30, 60, and 120 min or with 
hEGF (50 ng/mL) for 15 min were subjected to immunoblotting using anti-EGFR pY1068 or antiEGFR antibodies. (D) Analysis of CXCL8 in the supernatants from uninfected or B. henselaeinfected MSCs pre-treated or not for $6 \mathrm{~h}$ with a neutralizing anti-TLR2 antibody $(10 \mu \mathrm{g} / \mathrm{mL})$ or with the EGFR inhibitor gefitinib $(10 \mu \mathrm{M})$ or the RIP2K inhibitor GSK583 $(1 \mu \mathrm{M})$ and then stimulated for $96 \mathrm{~h}$. Data are shown as percentage (Mean \pm SEM) of CXCL8 production compared to DMSO or specific isotype control antibody-treated cells set at $100 \%$ ( $\mathrm{n}=6$ for antiTLR2; $\mathrm{n}=4$ for gefitinib, n=3 for GSK583; * $P<0.05$ vs $B$. henselae-infected cells; unpaired t-test). (E) To evaluate $B$. henselae internalization, MSC were pretreated for $6 \mathrm{~h}$ with the neutralizing anti-EGFR $(10 \mu \mathrm{g} / \mathrm{mL})$ or gefitinib $(10 \mu \mathrm{M})$, and percentages of intracellular bacteria were determined, after 1 and 2 days of incubation, respect to DMSO or specific isotype control antibody-treated cells set at $100 \%$. Data are shown as mean \pm SEM ( $n=4$ for gefitinib, $n=2$ for EGFR experiments performed in duplicate; * $P<0.05 v s$ internalized bacteria in untreated cells; unpaired t-test).

\section{FIG 5. Conditioned medium from $B$. henselae-infected MSCs curbs the infection rates and} angiogenic response of HUVECs. The effects of conditioned medium (CM) from $B$. henselaeinfected MSCs were tested by means of different angiogenic assays. (A) HUVEC monolayers were wounded with a 1.0-mm-wide rubber policeman and incubated in fresh medium supplemented with 5\% FCS and 1:2 diluted CM from infected (black bar, CM-MSC CTRL) or uninfected (white bar, CM-MSC B. henselae) MSCs. After 1 day, HUVECs invading the wound were quantified by digital imaging. Mean \pm SEM of 4 measurements per sample. ${ }^{*} P<0.05$ vs Ctrl; unpaired t-test. (B) Sprouting analysis of HUVEC spheroids. Spheroids were prepared in $20 \%$ methylcellulose medium, embedded in fibrin gel and stimulated with 1:2 diluted CM obtained from MSCs treated in the presence (black bar) or absence (white bar) of bacteria or with $30 \mathrm{ng} / \mathrm{ml}$ VEGF-A (dashed bar). The number of growing cell sprouts was counted after 1 day. Data are expressed as mean \pm SEM $(\mathrm{n}=10-20)$ and indicated as fold increase in the number of sprouts/spheroid $v s \mathrm{Ctrl} . * P<0.05 v s \mathrm{Ctrl}$; unpaired t-test. (C) The effect of CM from uninfected $v s$ B. henselae-infected MSCs on HUVEC 
morphogenesis was assessed by tube morphogenesis assay in three-dimensional (3D) collagen matrix. HUVECs were seeded $\left(40000 \mathrm{cells} / \mathrm{cm}^{2}\right)$ on Cultrex Extracellular Matrix in the presence of 1:2 diluted CM from uninfected (white bar) or B. henselae-infected MSCs (black bar). After $8 \mathrm{~h}$, the formation of capillary-like structures was examined. Representative images are shown in the left panels. The quantifications of capillary-like structure (right panel) are expressed as means \pm SEM relative to three measurements per sample. ${ }^{*} P<0.05$ vs $\mathrm{Ctrl}$; unpaired t-test. (D) Invasion rate of B. henselae in HUVECs (expressed as total CFUs) after 1 day of infection in the absence (grey bar) or presence of 1:2 diluted CM-MSC CTRL (white bar) and CM-MSC B. henselae (black bar). * $P<$ 0.05; unpaired t-test.

FIG 6. Angiogenic signature of $\boldsymbol{B}$. henselae-infected MSCs. (A) Human angiogenesis antibody array analysis was performed using a pool of supernatants from $96 \mathrm{~h}$ uninfected MSC (CTRL) or $B$. henselae-infected MSCs. Some of the most representative angiogenic factors are highlighted in different colors. The graph with normalized pixel density of all the visualized spots is shown in Fig. S1 in the supplemental material. (B) Heat map analysis representing the normalized average pixel density of the pair of duplicate spots for each angiogenic-related protein in the array. (C) Quantification of VEGF-A, CXCL8, IL-6, CCL5 and PDGF-D production in uninfected (CTRL) and B. henselae-infected MSCs. Data are expressed as mean \pm SEM of 3 independent experiments. $* \mathrm{P}<0.05$ vs CTRL; unpaired t-test. nd= not detectable. 
Figure 1

A

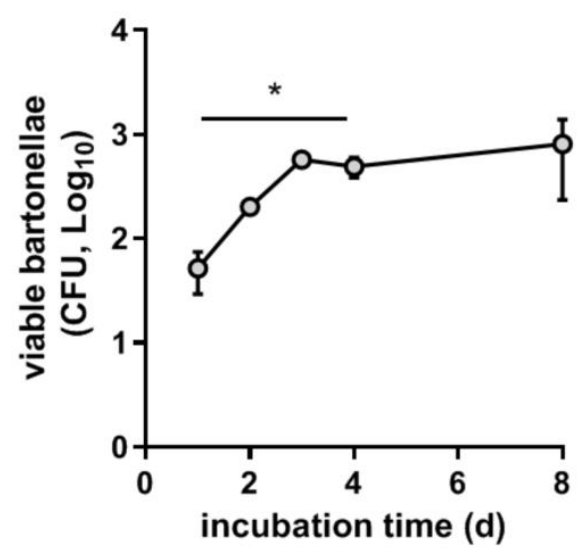

C

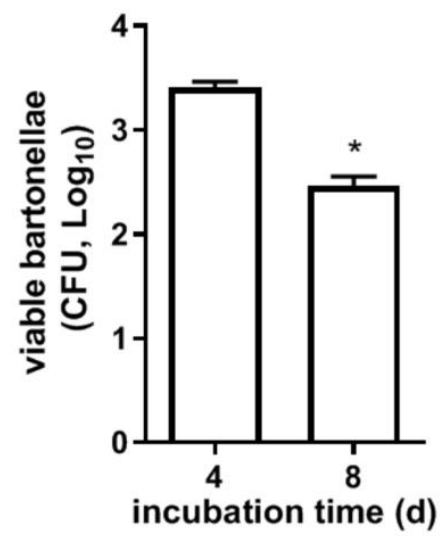

B

CTRL

B. henselae

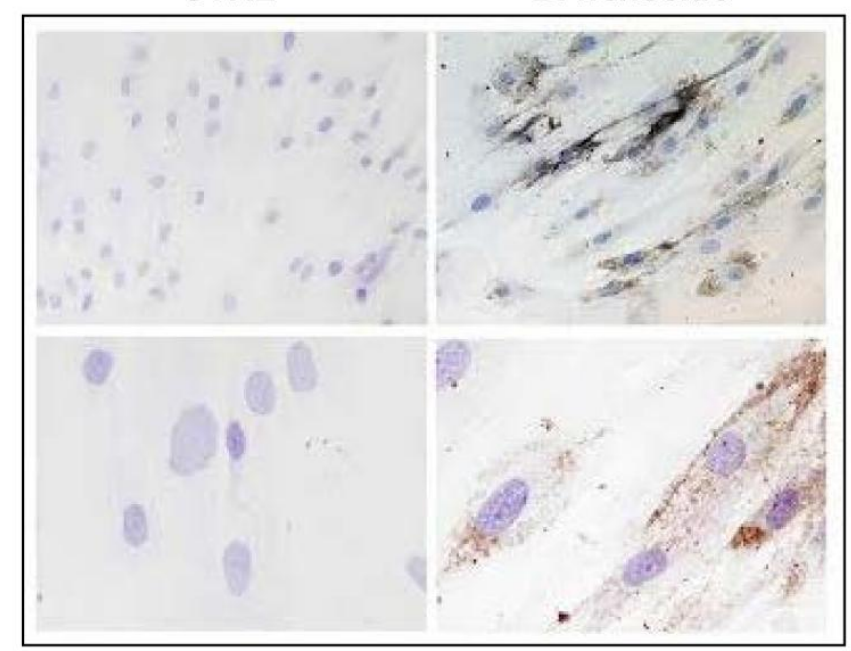

D

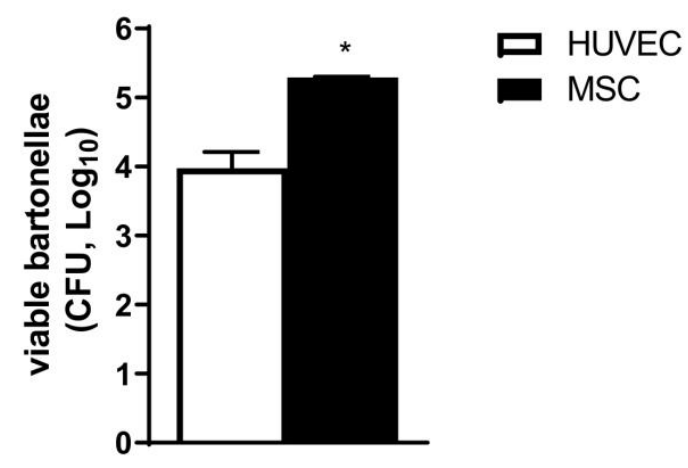




\section{$757 \quad$ Figure 2}

A

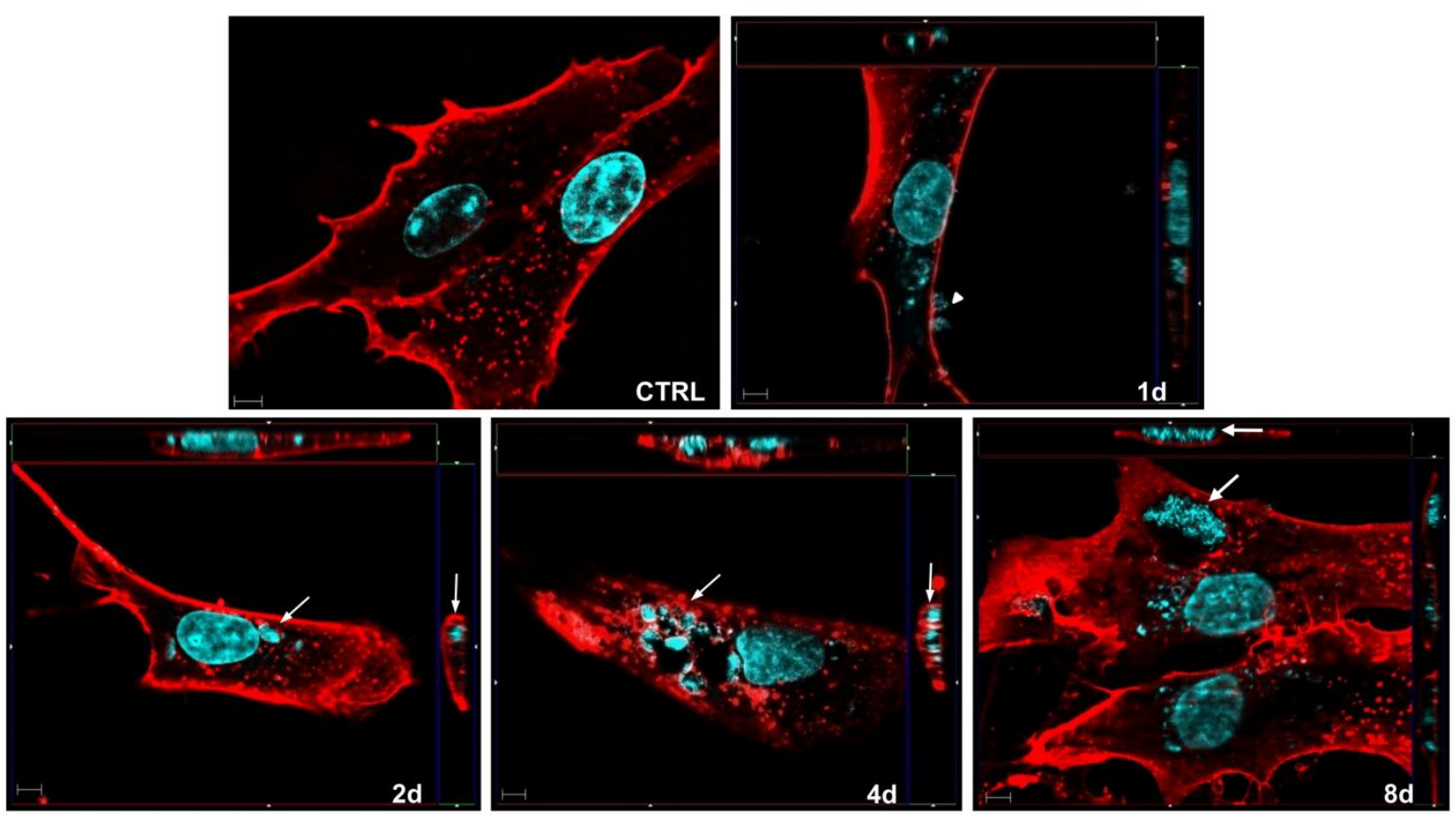

B
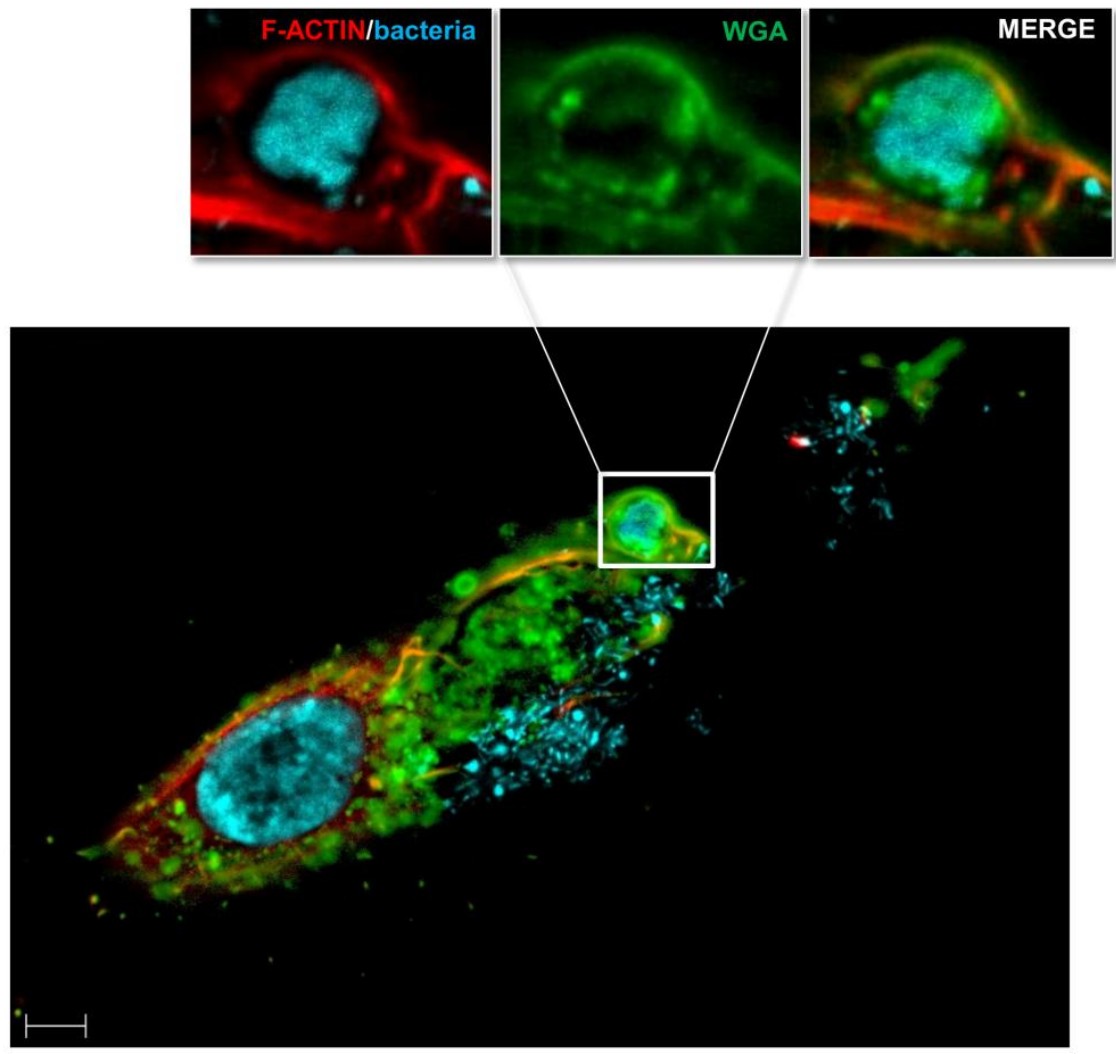
Figure 3

A

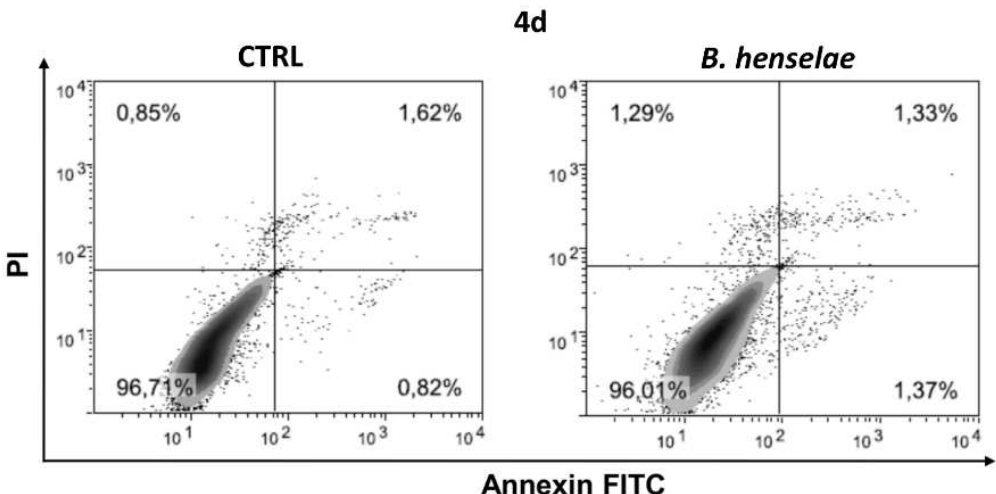

B

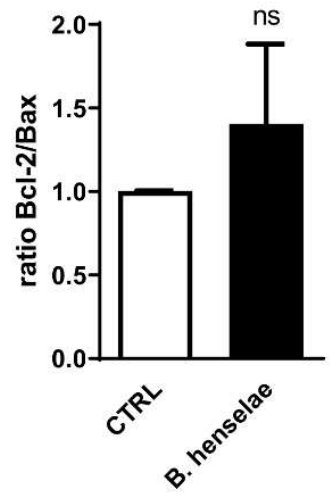

C

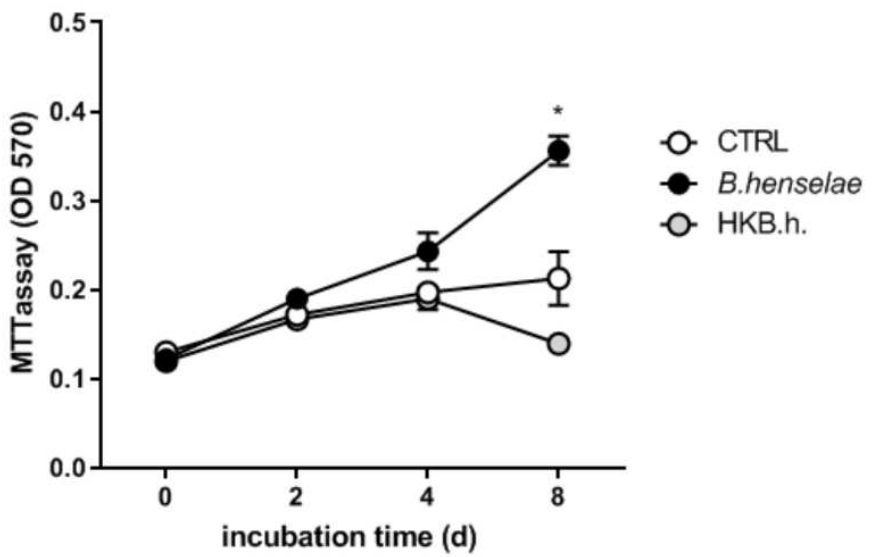


A
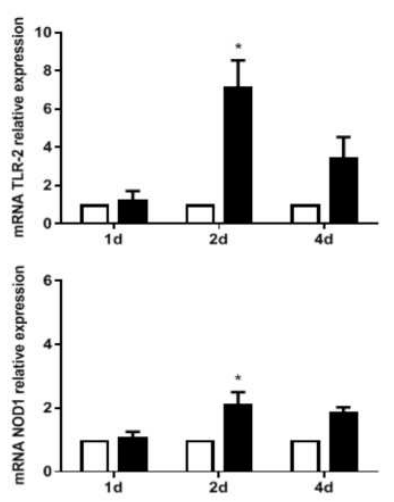

C

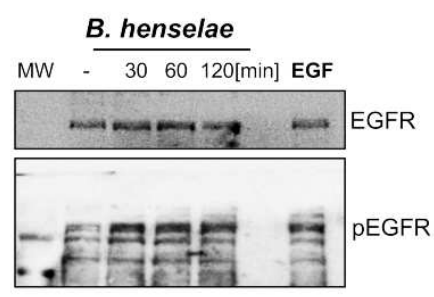

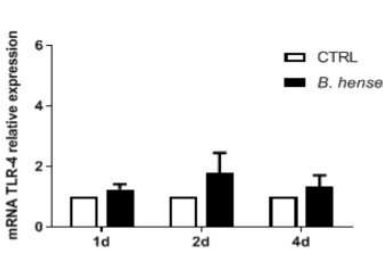
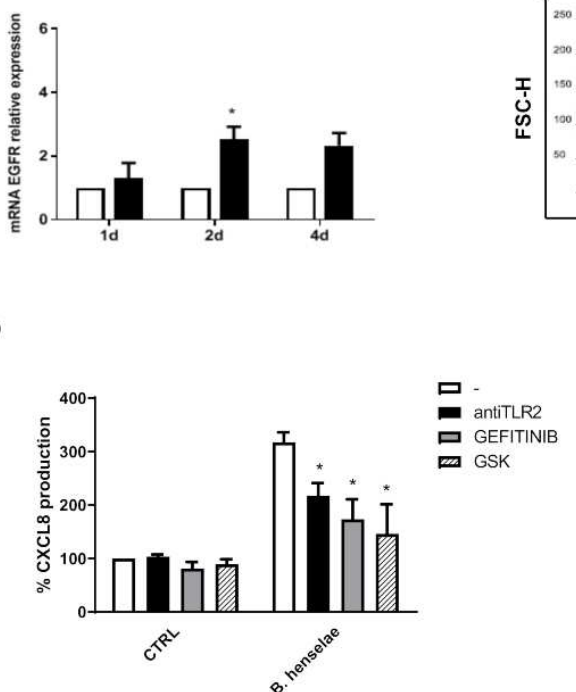

B
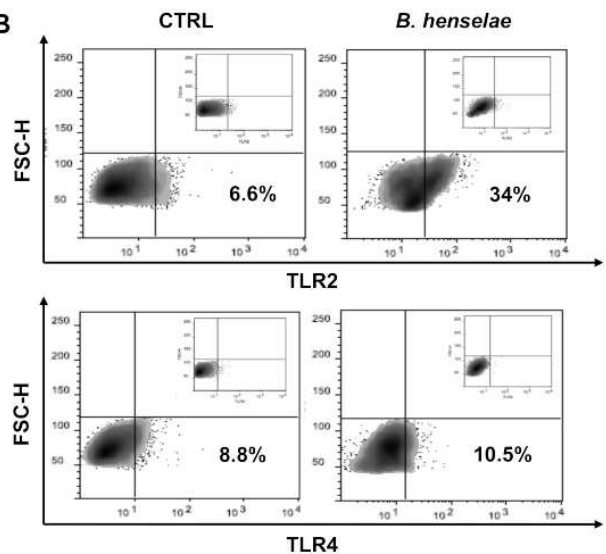

E 


\section{Figure 5}

A
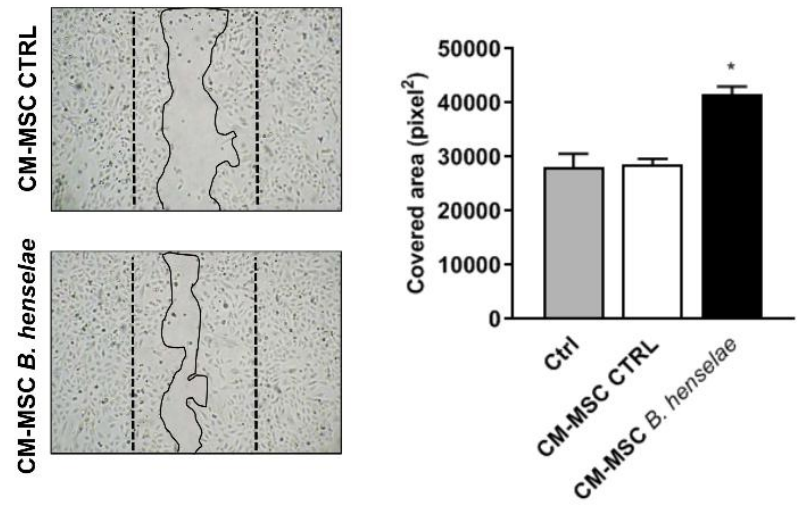

C
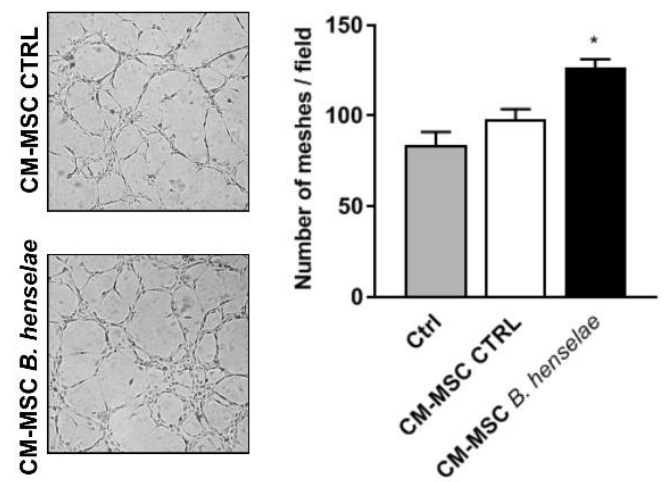
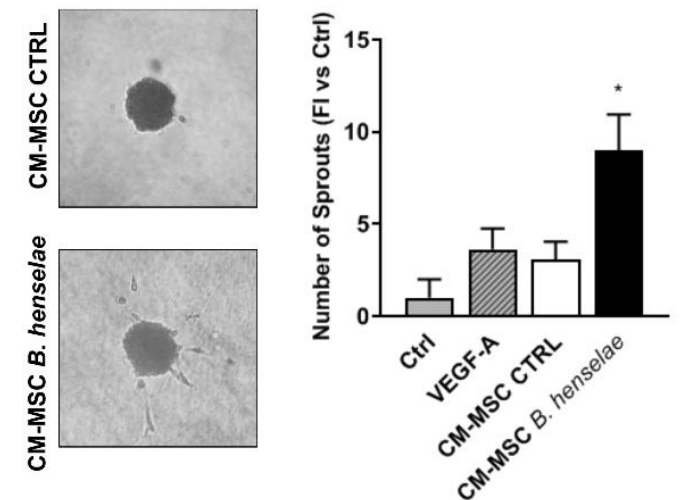

D
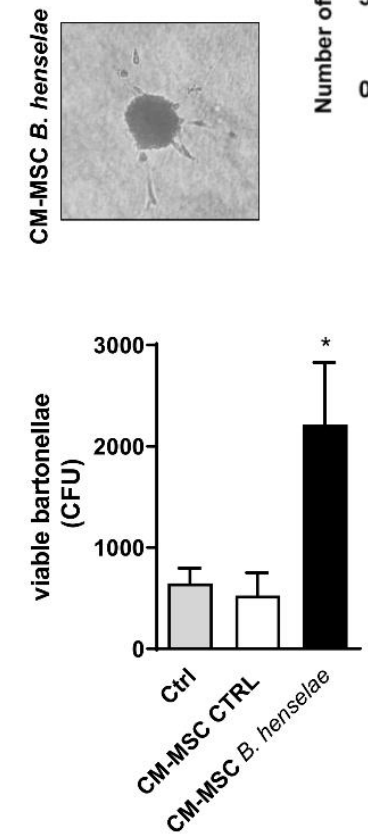

796

797

798

799

800

801

802

803

804

805

806

807

808

809

810 
$812 \quad$ Figure 6
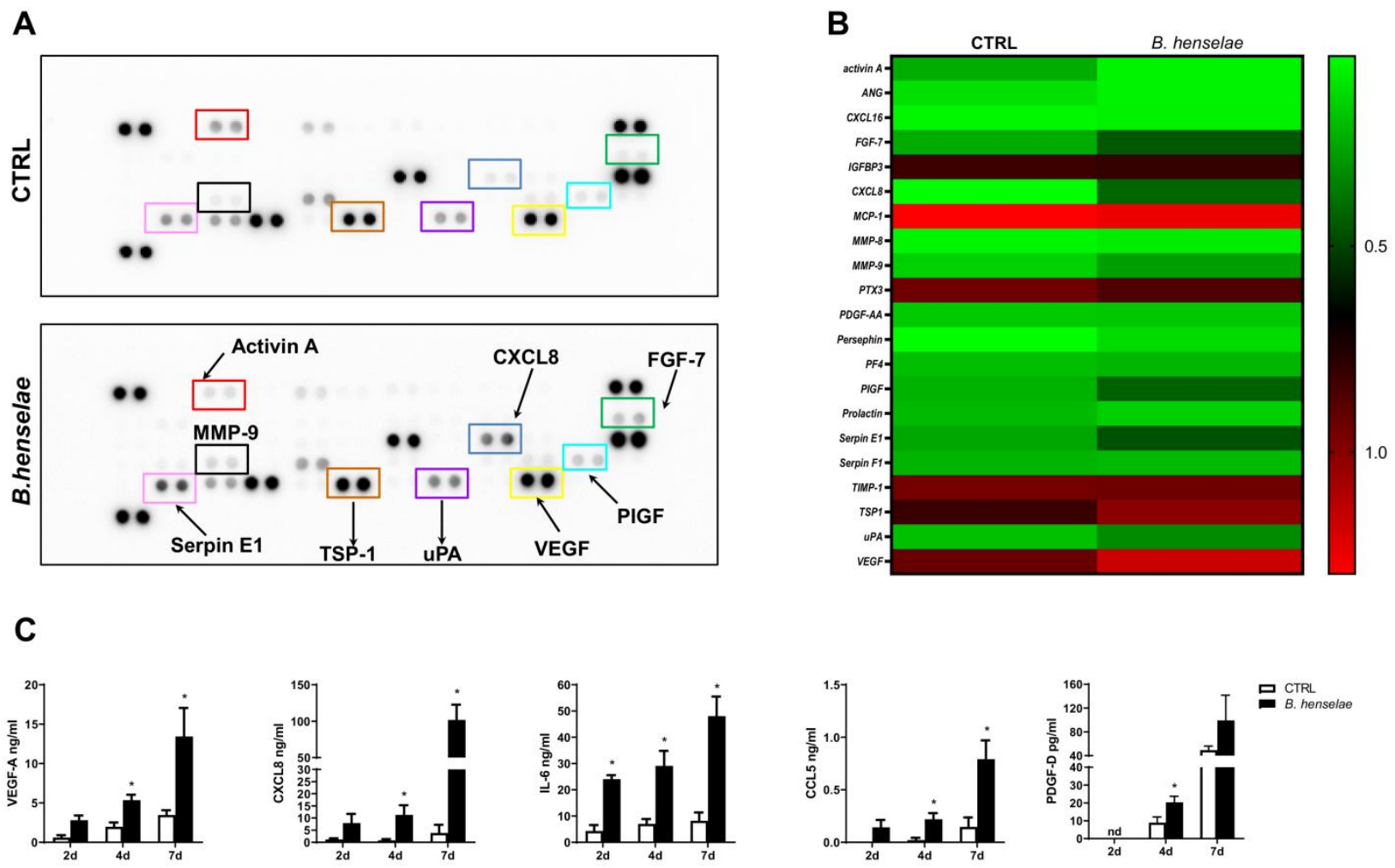

813

814

815

816

817

818

819

820

821

822

823

824

825

826

827

828

829 
A

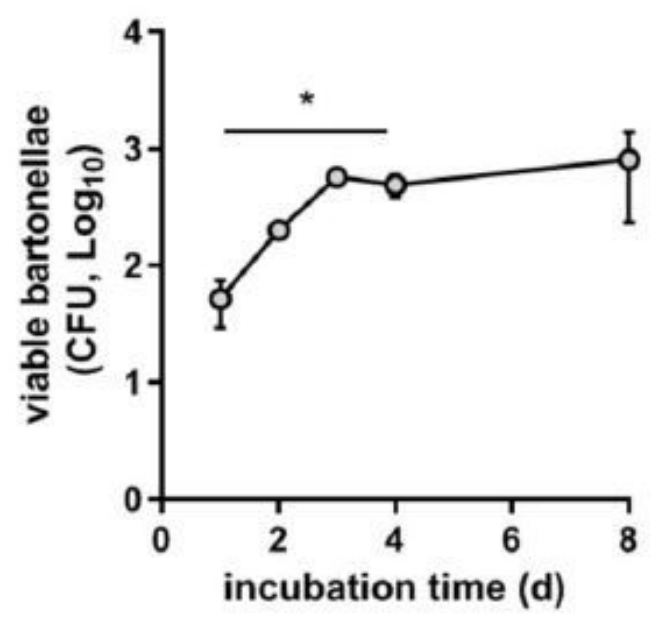

C

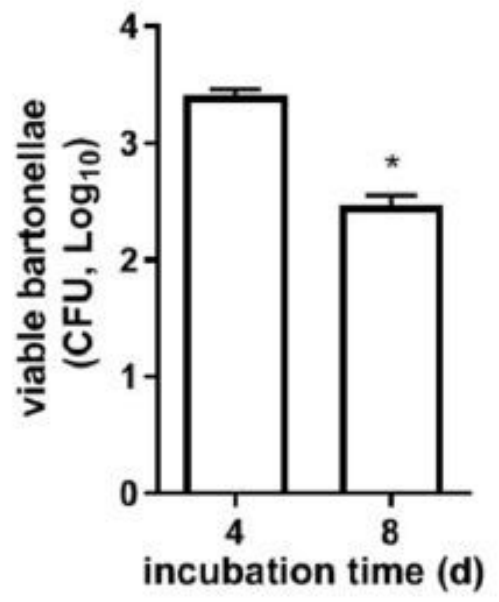

B

CTRL

B. henselae

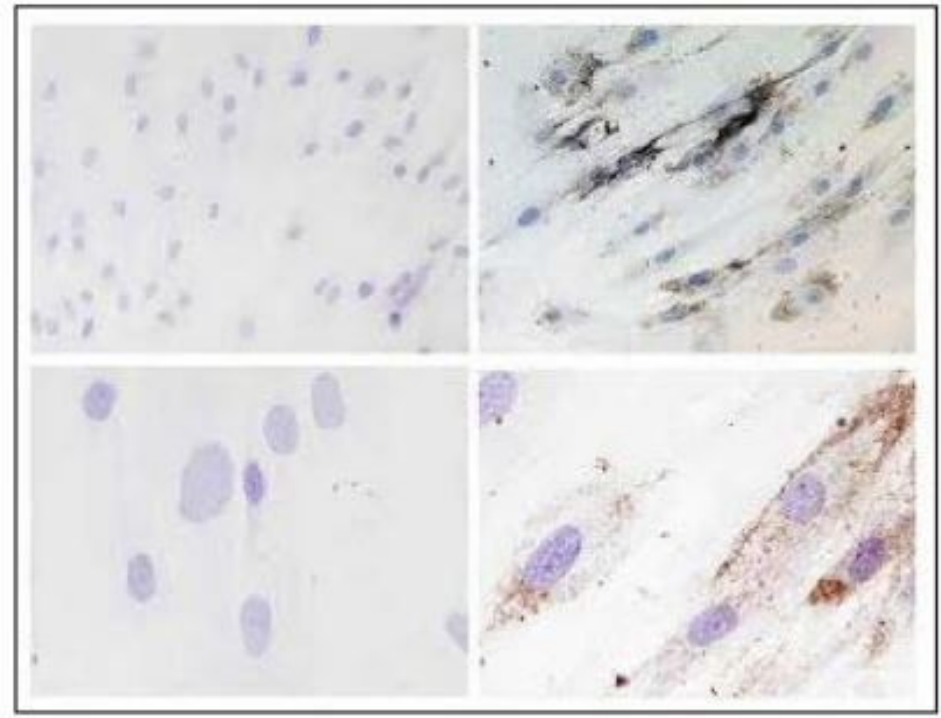

D

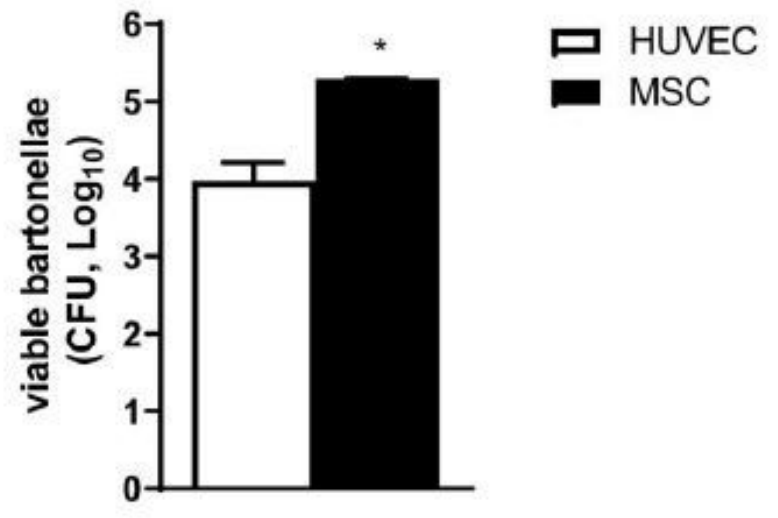

\section{Figure 1}

B. henselae invades and persists in MSCs. (A) Invasion rates of B. henselae into MSCs were measured at day $1,2,3,4$ and 8 pi by gentamicin protection assay (GPA). After infection, cells were treated with gentamicin, and the number of intracellular bacteria was determined by CFU count. Data are expressed as means \pm SEM from two independent experiments carried out in triplicate ( ${ }^{*} P<0.05$ vs Log 10 CFU at $1 \mathrm{~d}$; unpaired t-test). (B) Uninfected (CTRL) or B. henselae- infected MSCs (8 days) were immunostained with an anti-BH antibody and counterstained with hematoxylin (upper panel 20X, lower panel 40X). (C) To determine intracellular survival after 4 days of infection, extracellular bacteria were killed by gentamicin treatment and incubated in normal medium for the indicated times. Mean values \pm SEM of triplicate samples are representative of three independent experiments. ( ${ }^{\star} P<0.05$; unpaired t-test). (D) Invasion 
rates of B. henselae in MSCs or HUVECs (60,000 cells each, respectively). The number of intracellular bacteria as Log10 CFU was quantified at 1 day pi (*P < 0.05 MSCs vs HUVECs; unpaired t-test).

A

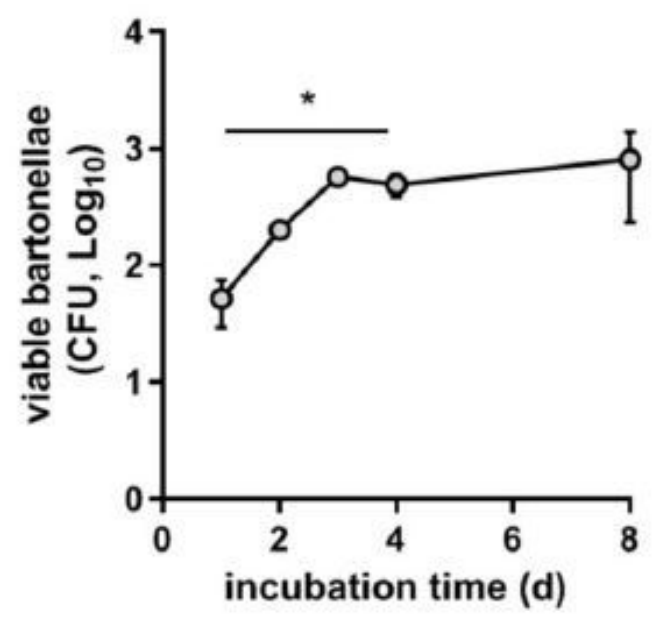

C

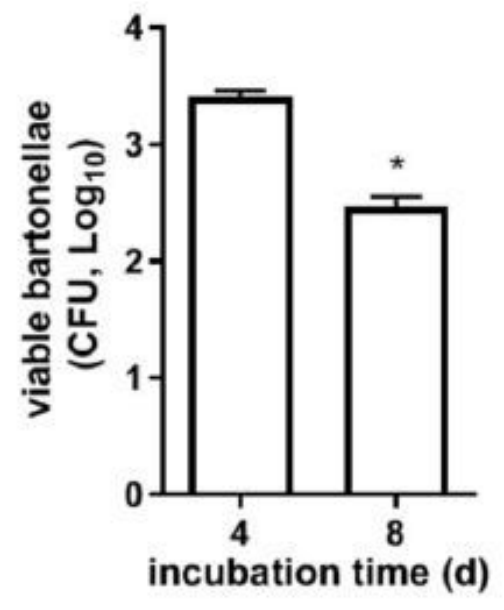

B

CTRL

B. henselae

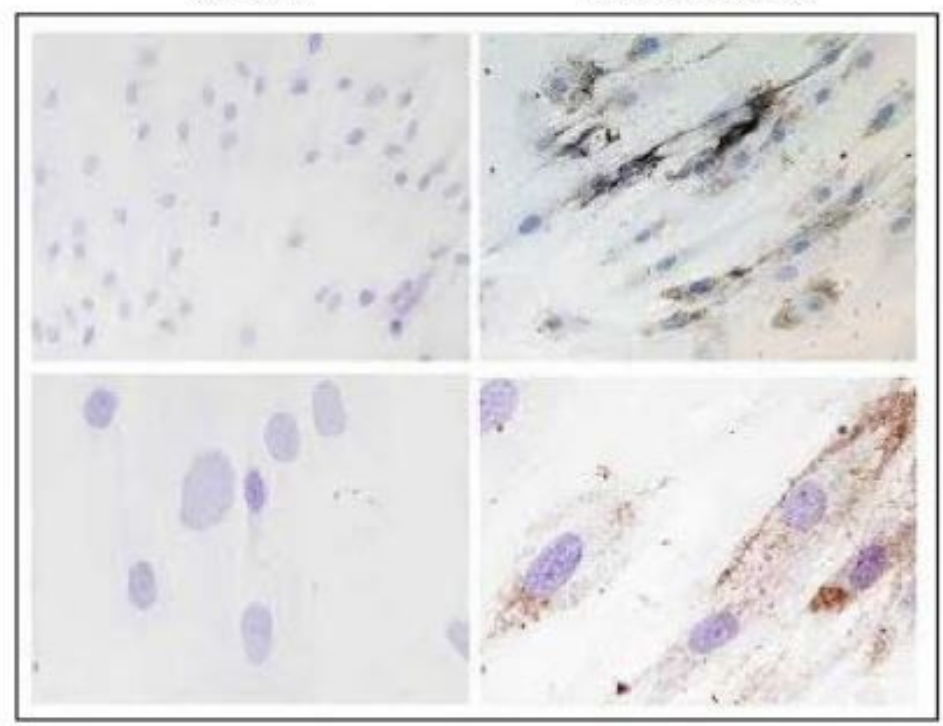

D

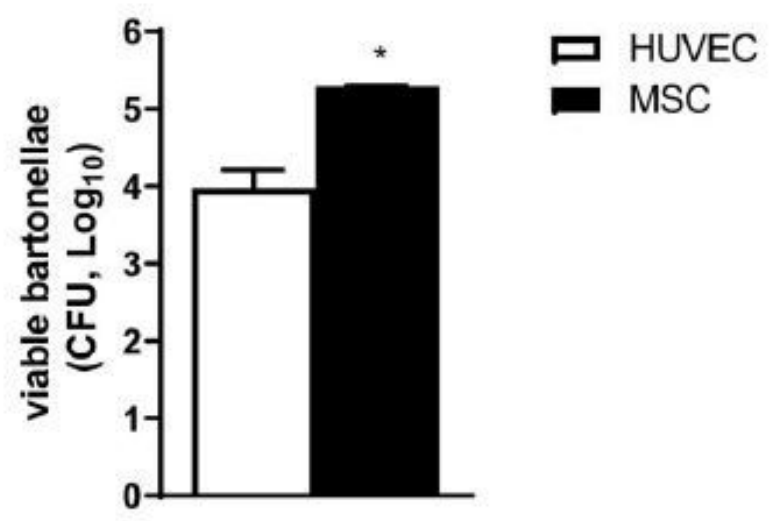

\section{Figure 1}

B. henselae invades and persists in MSCs. (A) Invasion rates of B. henselae into MSCs were measured at day 1, 2, 3, 4 and 8 pi by gentamicin protection assay (GPA). After infection, cells were treated with gentamicin, and the number of intracellular bacteria was determined by CFU count. Data are expressed as means \pm SEM from two independent experiments carried out in triplicate ( ${ }^{*} P<0.05$ vs Log 10 CFU at $1 \mathrm{~d}$; unpaired t-test). (B) Uninfected (CTRL) or B. henselae- infected MSCs (8 days) were immunostained with an anti-BH antibody and counterstained with hematoxylin (upper panel 20X, lower panel 40X). (C) To determine intracellular survival after 4 days of infection, extracellular bacteria were killed by gentamicin treatment and incubated in normal medium for the indicated times. Mean values \pm SEM of triplicate samples are representative of three independent experiments. ( ${ }^{\star} \mathrm{P}<0.05$; unpaired $t$-test). (D) Invasion 
rates of B. henselae in MSCs or HUVECs (60,000 cells each, respectively). The number of intracellular bacteria as Log10 CFU was quantified at 1 day pi ( ${ }^{*} P<0.05$ MSCs vs HUVECs; unpaired t-test).

A

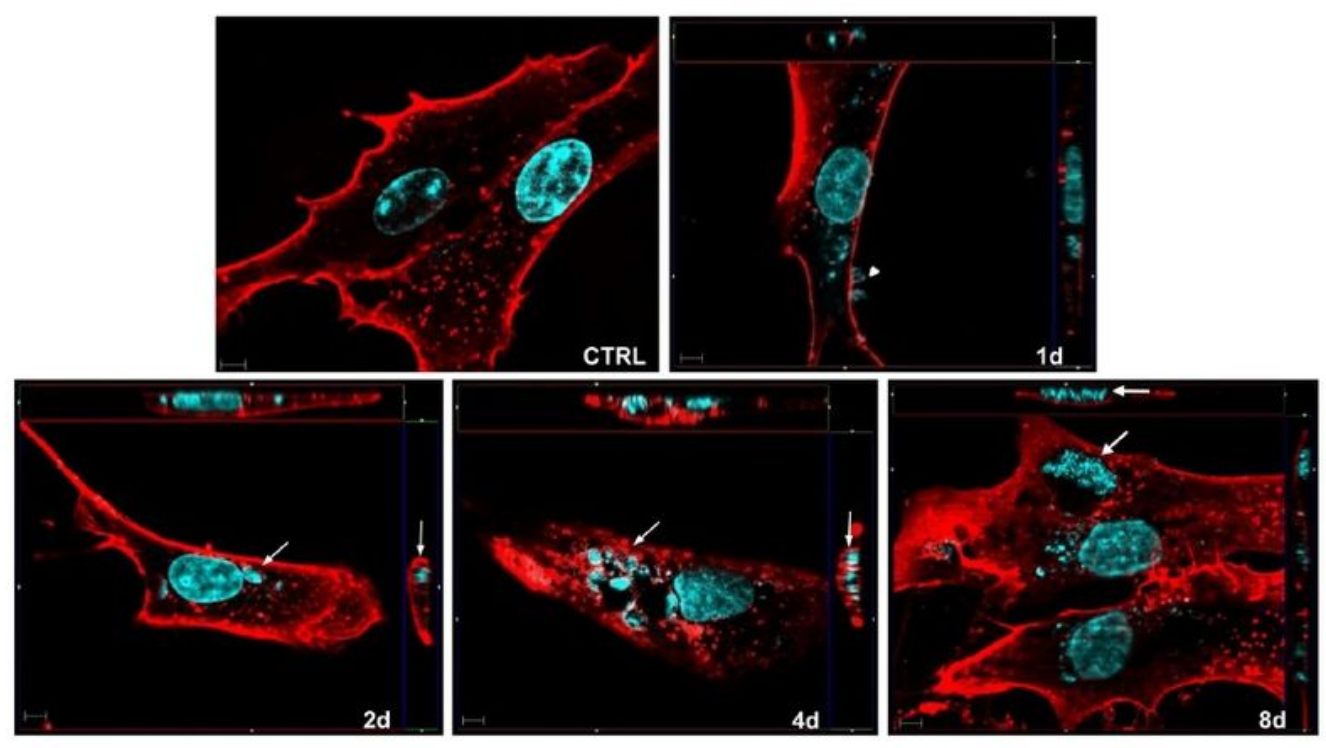

B
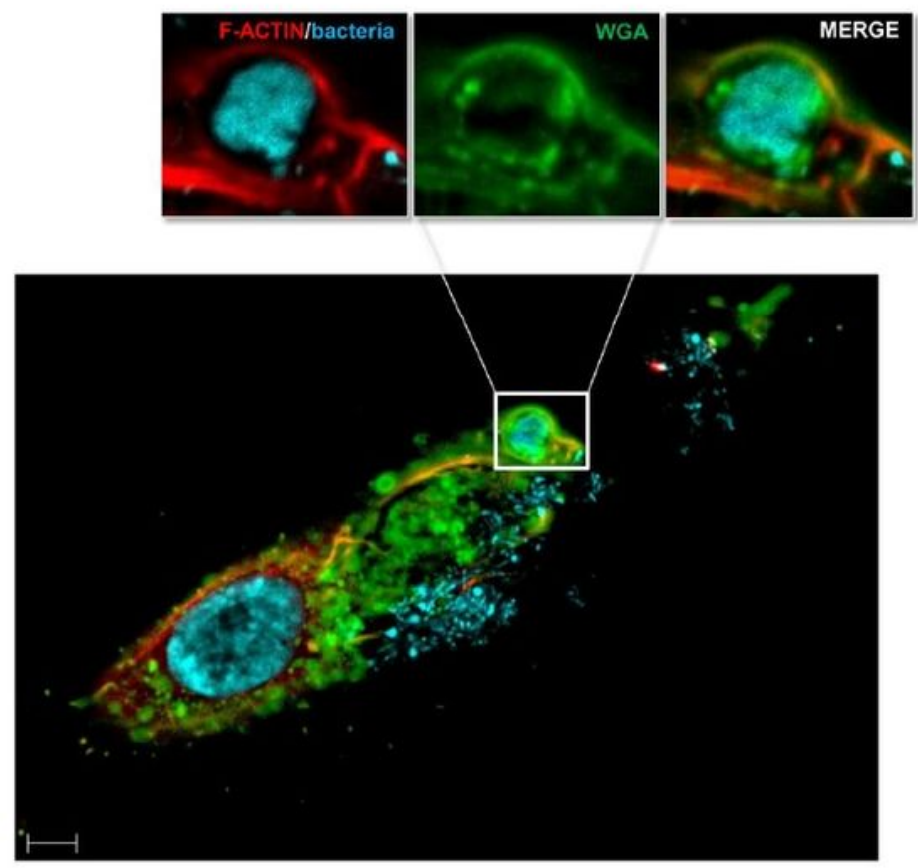

Figure 2

B. henselae localizes in invasome structures in MSCs. (A) Immunofluorescence of B. henselae-infected MSCs at 1, 2, 4 and 8 days pi and uninfected control MSCs (CTLR). B. henselae and cell membranes were stained with DAPI (cyan) and wheat germ agglutinin-Alexa Fluor 594 (red), respectively, and analyzed 
with an epifluorescence microscope. Bacteria anchored to the MSC membrane are indicated with arrowheads. The thin arrows ( 2 and 4 days) indicate internalized bacteria within membrane bound compartments in the perinuclear area, whereas the large arrows (8 days) highlight sizeable intracellular bacterial aggregates called invasomes. Each image also shows the basal portion of adherent MSC cells, with the orthogonal $z$ reconstruction of the whole cell. (B) Representative image of an invasome. MSCs were infected with B. henselae for 8 days and then washed and fixed with PFA. Samples were stained for F-actin (red), wheat germ agglutinin (WGA) (green) and DAPI and analyzed as described in panel A (bar: $10 \mu \mathrm{m})$. 
A

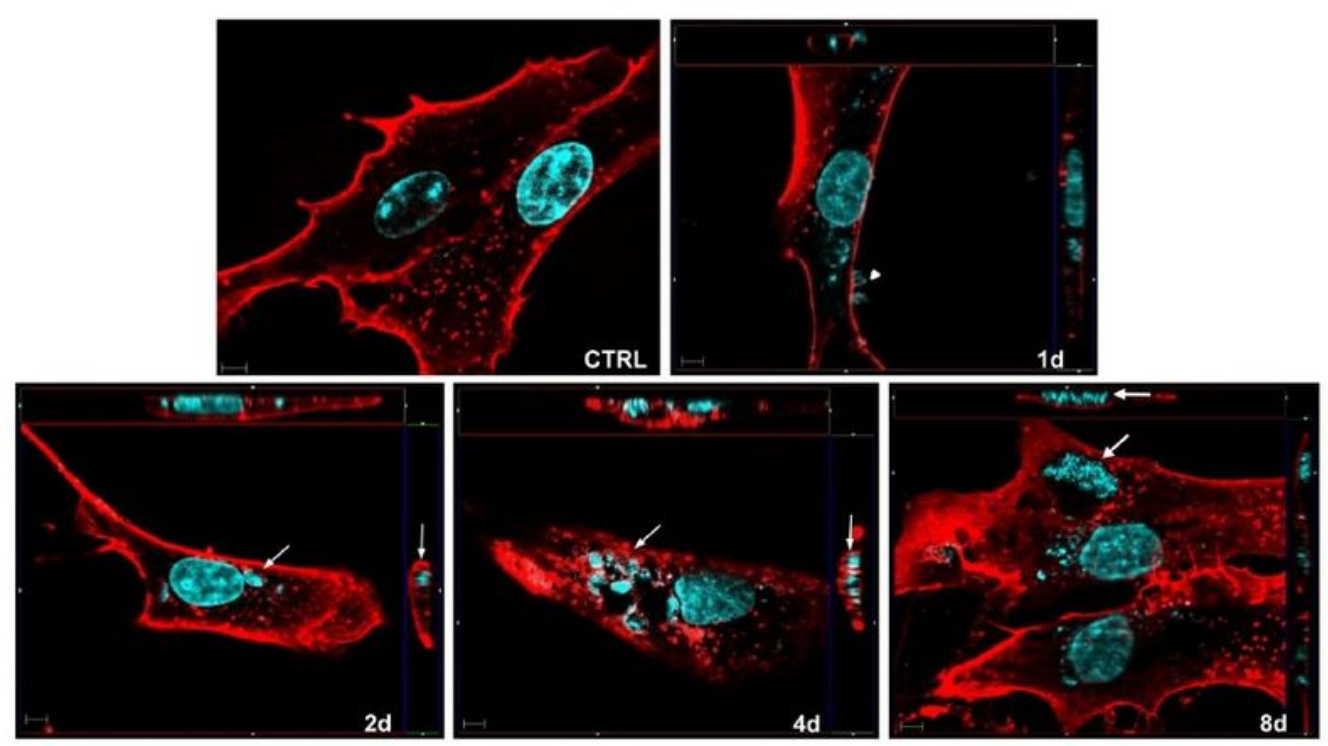

B

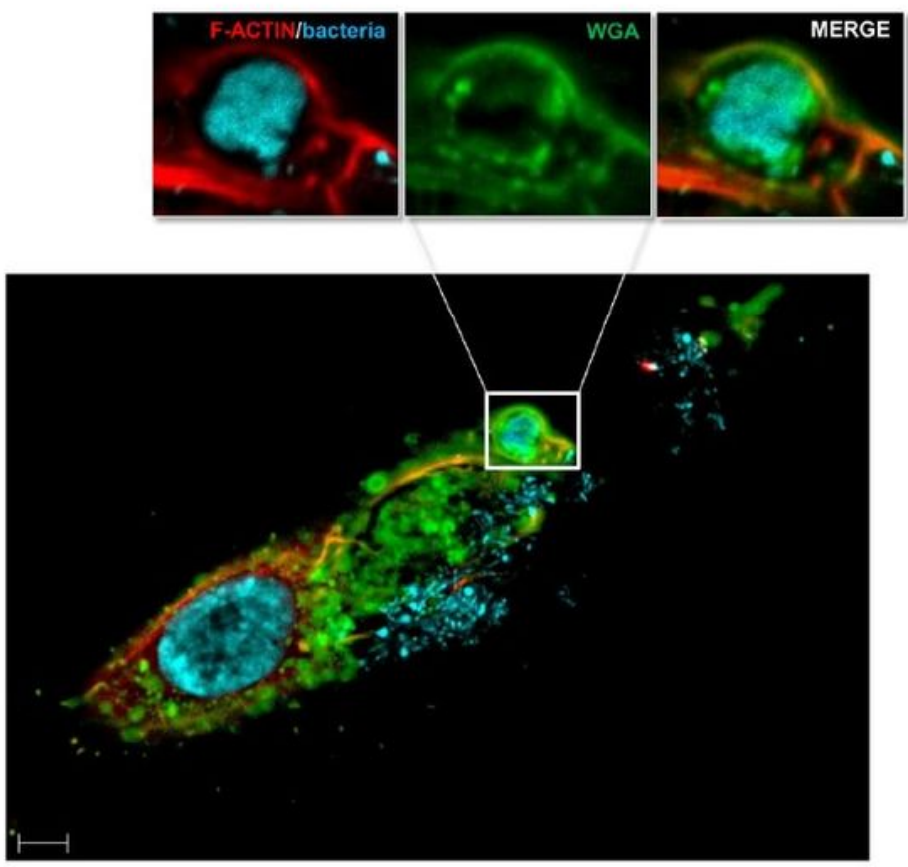

\section{Figure 2}

B. henselae localizes in invasome structures in MSCs. (A) Immunofluorescence of B. henselae-infected MSCs at 1, 2, 4 and 8 days pi and uninfected control MSCs (CTLR). B. henselae and cell membranes were stained with DAPI (cyan) and wheat germ agglutinin-Alexa Fluor 594 (red), respectively, and analyzed with an epifluorescence microscope. Bacteria anchored to the MSC membrane are indicated with arrowheads. The thin arrows ( 2 and 4 days) indicate internalized bacteria within membrane bound 
compartments in the perinuclear area, whereas the large arrows (8 days) highlight sizeable intracellular bacterial aggregates called invasomes. Each image also shows the basal portion of adherent MSC cells, with the orthogonal $z$ reconstruction of the whole cell. (B) Representative image of an invasome. MSCs were infected with B. henselae for 8 days and then washed and fixed with PFA. Samples were stained for F-actin (red), wheat germ agglutinin (WGA) (green) and DAPI and analyzed as described in panel A (bar: $10 \mu \mathrm{m})$.

A

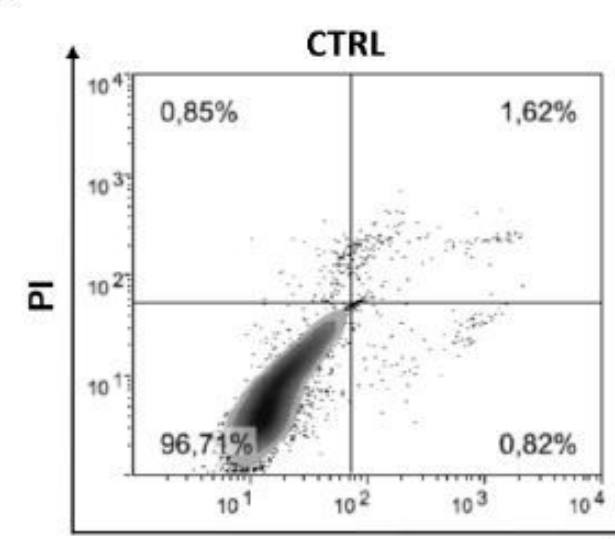

$4 d$

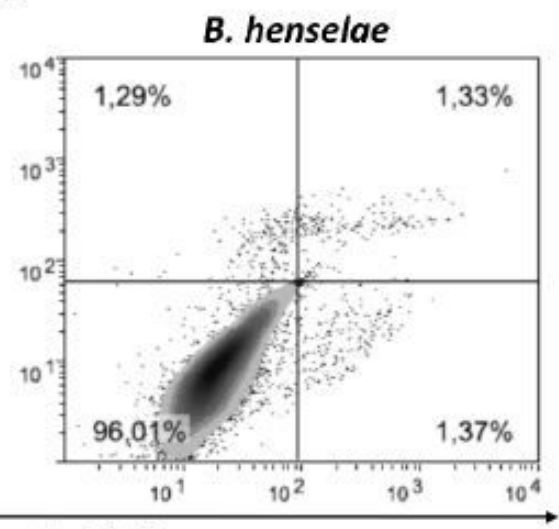

Annexin FITC

C
B

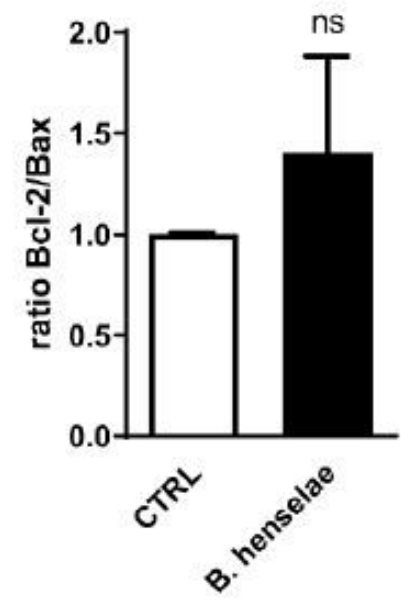

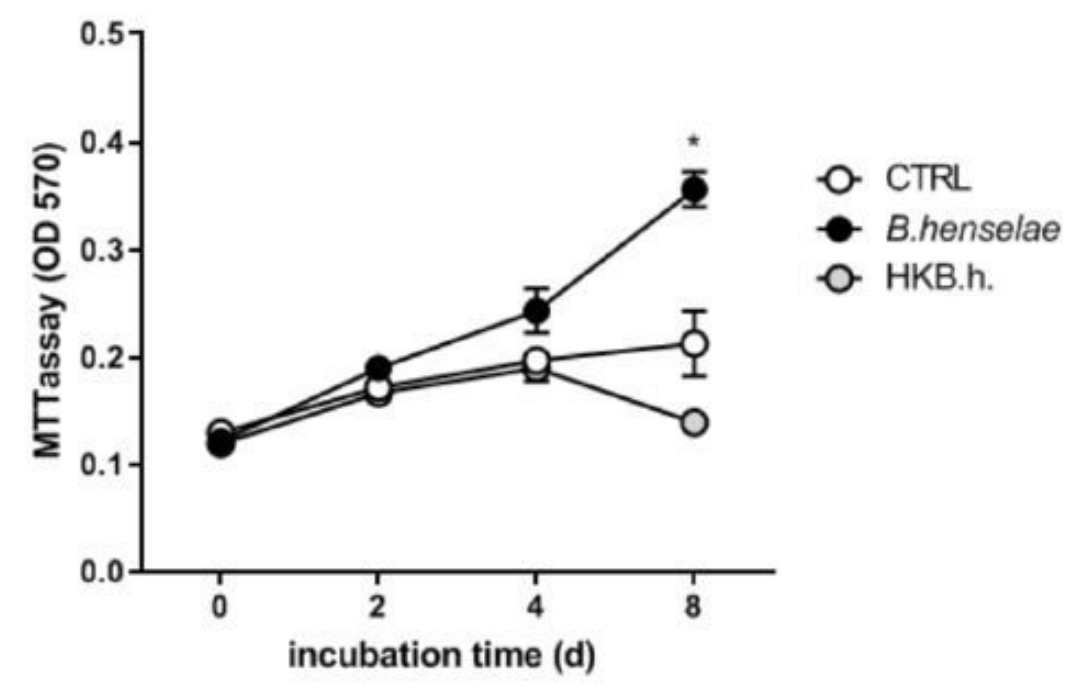

Figure 3

B. henselae favors the proliferation of infected MSCs. (A) MSC death was evaluated by FACS analysis after 4 days of infection with B. henselae. Uninfected MSCs (left panel; CTRL) and infected MSCs (right panel; B. henselae) were double-stained with FITC-annexin V and PI. Counterstaining with PI allowed differentiation of necrotic cells (upper left quadrant of the dot plot), late apoptotic cells (upper right quadrant) and early apoptotic cells (lower right quadrant). The percentages of cells localizing to these quadrants are indicated in each quadrant. Data are representative of 3independent experiments. (B) The 
Bcl-2/Bax expression ratio was analyzed in control and B. henselae-infected MSCs at 2 days pi by qPCR. Gene expression was normalized to HPRT. Data are expressed as means \pm SEM of 4 independent experiments (ns not significant; unpaired t-test). (C) Proliferation assay. MSCs were treated as indicated for $0,2,4$, and 8 days and analyzed by MTT assay. Untreated MSCs (white circle); B. henselae infected MSC (black circle); and heat killed B. henselae-treated MSCs (HKB.h.) (grey circle). Data are expressed as means \pm SEM of triplicate samples of one experiment representative of 3 independent ones $\left({ }^{\star} P<0.05 B\right.$. henselae vs CTRL, unpaired t-test).

A

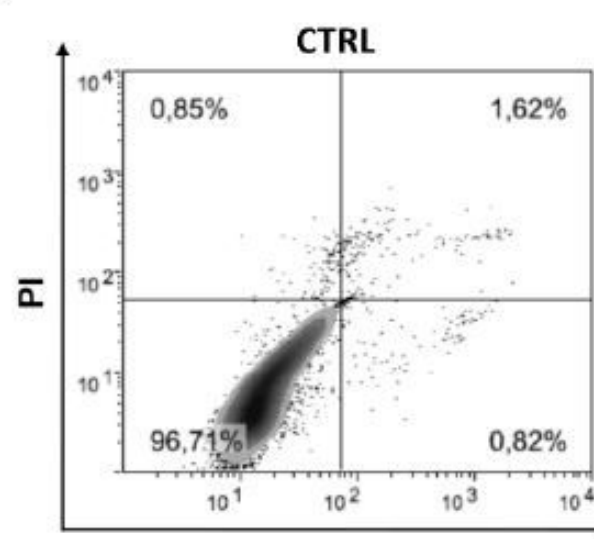

4d

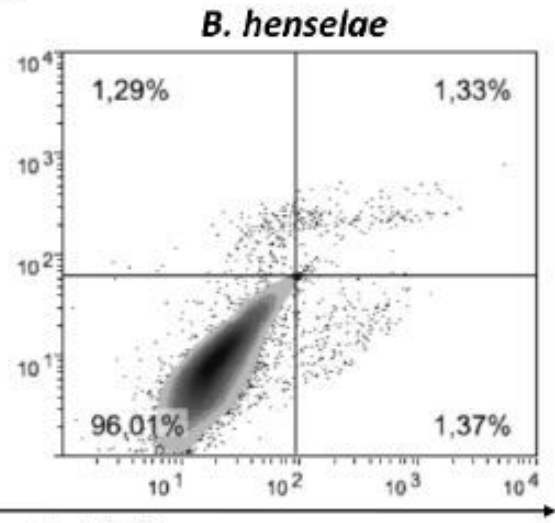

Annexin FITC

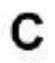

B

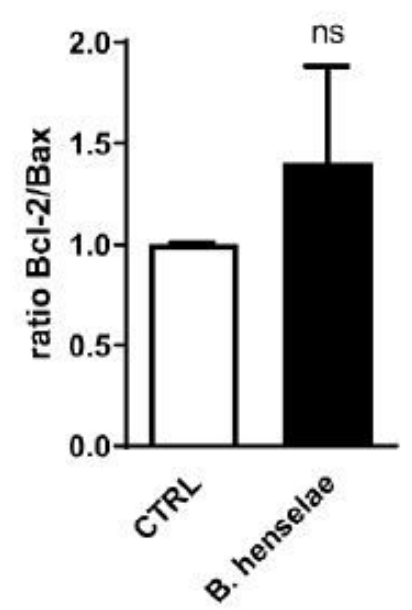

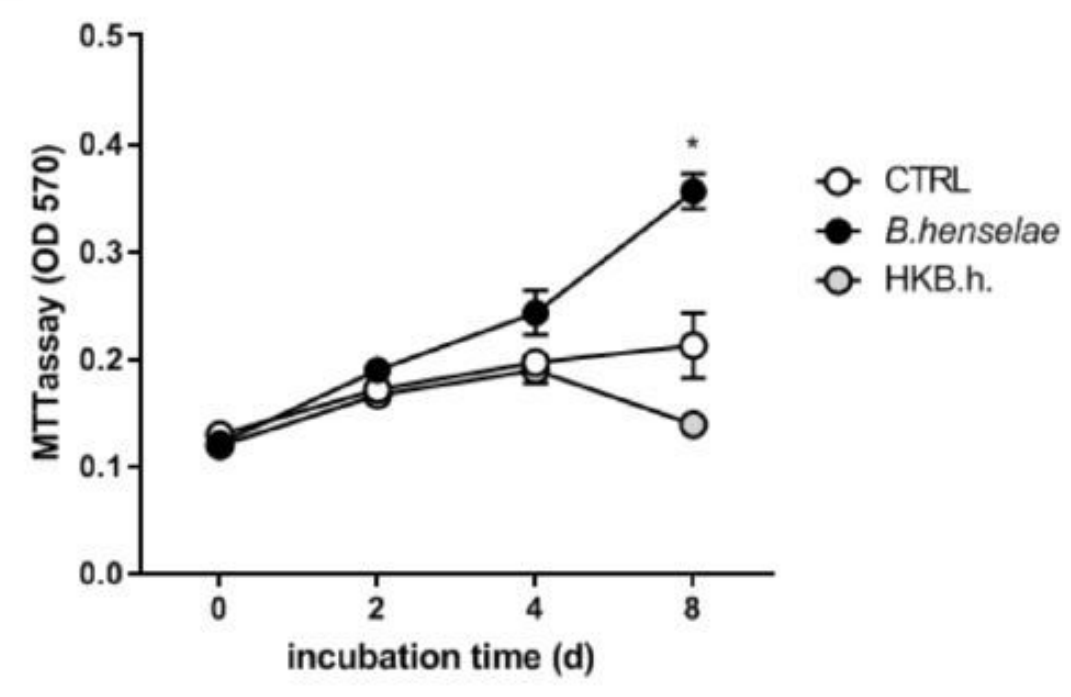

Figure 3

B. henselae favors the proliferation of infected MSCs. (A) MSC death was evaluated by FACS analysis after 4 days of infection with B. henselae. Uninfected MSCs (left panel; CTRL) and infected MSCs (right panel; B. henselae) were double-stained with FITC-annexin V and PI. Counterstaining with PI allowed differentiation of necrotic cells (upper left quadrant of the dot plot), late apoptotic cells (upper right quadrant) and early apoptotic cells (lower right quadrant). The percentages of cells localizing to these 
quadrants are indicated in each quadrant. Data are representative of 3independent experiments. (B) The Bcl-2/Bax expression ratio was analyzed in control and B. henselae-infected MSCs at 2 days pi by qPCR. Gene expression was normalized to HPRT. Data are expressed as means \pm SEM of 4 independent experiments (ns not significant; unpaired t-test). (C) Proliferation assay. MSCs were treated as indicated for $0,2,4$, and 8 days and analyzed by MTT assay. Untreated MSCs (white circle); B. henselae infected MSC (black circle); and heat killed B. henselae-treated MSCs (HKB.h.) (grey circle). Data are expressed as means \pm SEM of triplicate samples of one experiment representative of 3 independent ones $\left({ }^{*} P<0.05 B\right.$. henselae vs CTRL, unpaired t-test).

A
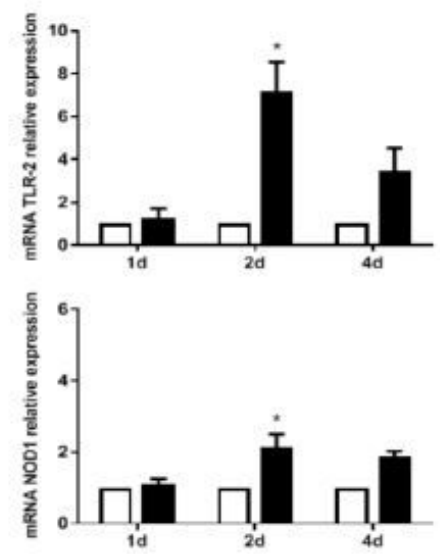

C

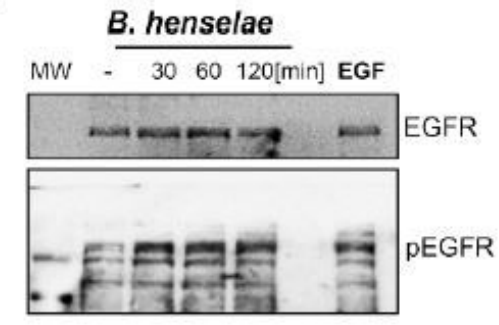

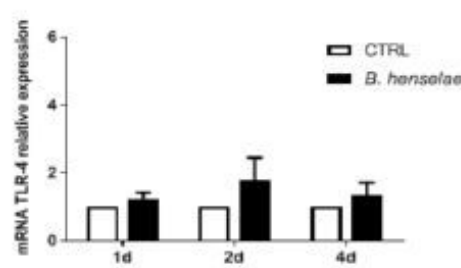

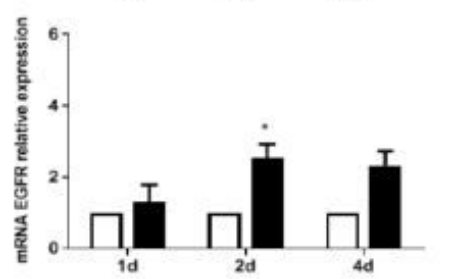

D

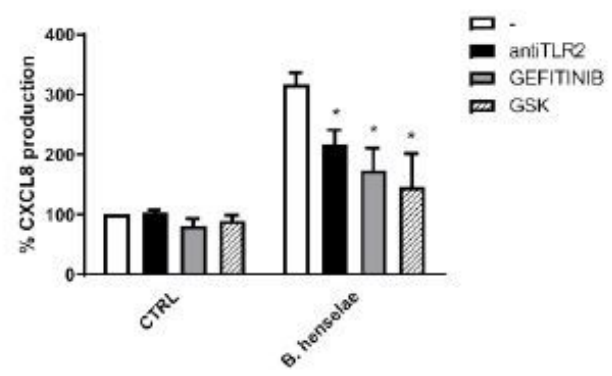

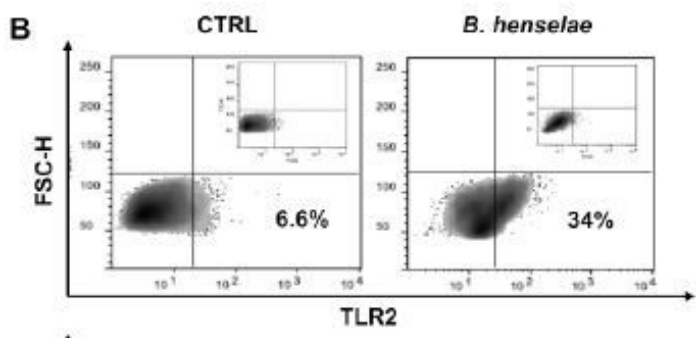

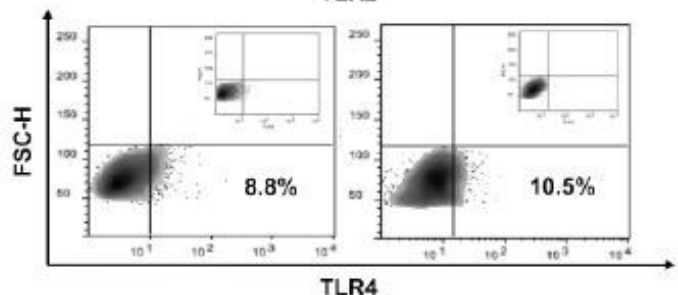

E

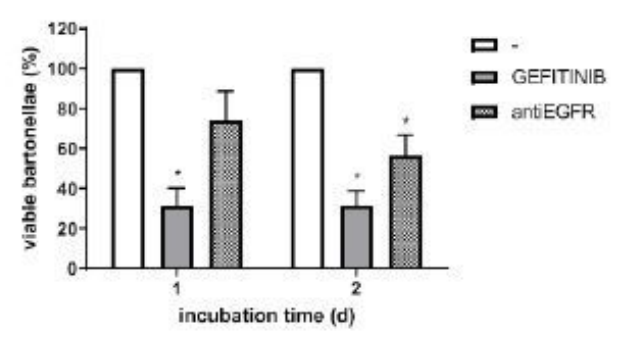

\section{Figure 4}

Expression of TLR2, NOD1 and EGFR in B. henselae-infected MSCs. (A) mRNA expression levels of TLR2, TLR4, NOD1 and EGFR in uninfected (white bar) and B. henselae-infected MSCs (black bar) were determined by qPCR and normalized to RPL13A. Data are expressed as means \pm SEM of four independent experiments ( $\mathrm{P}<0.05$; unpaired t-test). (B) TLR2 and TLR4 protein expression levels on MSC membranes were analyzed by FACS in MSCs at $4 \mathrm{~d}$ pi. Cells were immunostained with anti-TLR2, anti-TLR4 or specific isotype control antibodies. The percentages of positive cells are indicated in each quadrant. Fluorescence minus one (FMO) controls for the antibodies are shown as well. Data are representative of three independent experiments. (C) Cell extracts from MSCs infected with B. henselae for 30,60 , and 120 min or with hEGF $(50 \mathrm{ng} / \mathrm{mL})$ for 15 min were subjected to immunoblotting using antiEGFR pY1068 or anti-EGFR antibodies. (D) Analysis of CXCL8 in the supernatants from uninfected or B. 
henselae-infected MSCs pre-treated or not for $6 \mathrm{~h}$ with a neutralizing anti-TLR2 antibody $(10 \mu \mathrm{g} / \mathrm{mL})$ or with the EGFR inhibitor gefitinib $(10 \mu \mathrm{M})$ or the RIP2K inhibitor GSK583 $(1 \mu \mathrm{M})$ and then stimulated for 96 h. Data are shown as percentage (Mean \pm SEM) of CXCL8 production compared to DMSO or specific isotype control antibody-treated cells set at $100 \%$ ( $n=6$ for antiTLR2; $n=4$ for gefitinib, $n=3$ for GSK583; * P $<0.05$ vs $B$. henselae-infected cells; unpaired t-test). (E) To evaluate $B$. henselae internalization, MSC were pretreated for $6 \mathrm{~h}$ with the neutralizing anti-EGFR $(10 \mu \mathrm{g} / \mathrm{mL})$ or gefitinib $(10 \mu \mathrm{M})$, and percentages of intracellular bacteria were determined, after 1 and 2 days of incubation, respect to DMSO or specific isotype control antibody-treated cells set at $100 \%$. Data are shown as mean \pm SEM $(n=4$ for gefitinib, $n=2$ for EGFR experiments performed in duplicate; ${ }^{*} \mathrm{P}<0.05$ vs internalized bacteria in untreated cells; unpaired t-test).

A
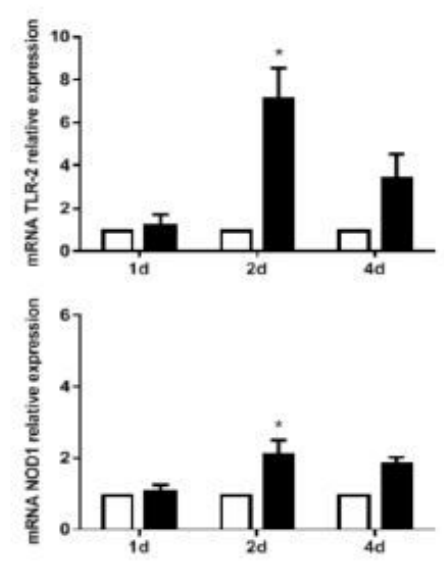

C

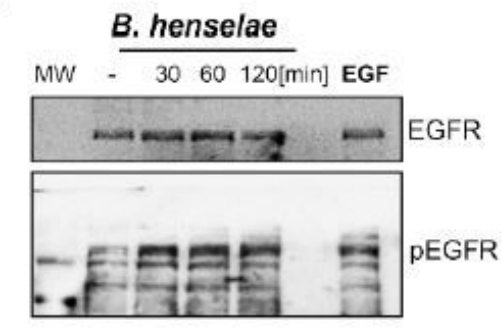

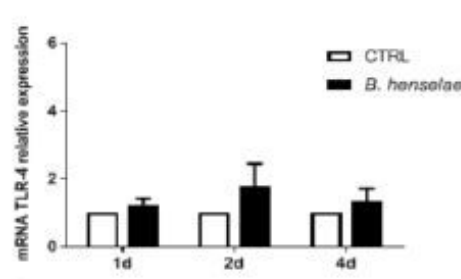

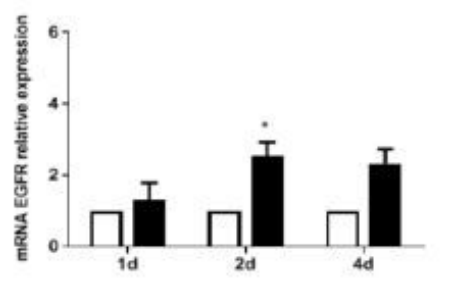

D
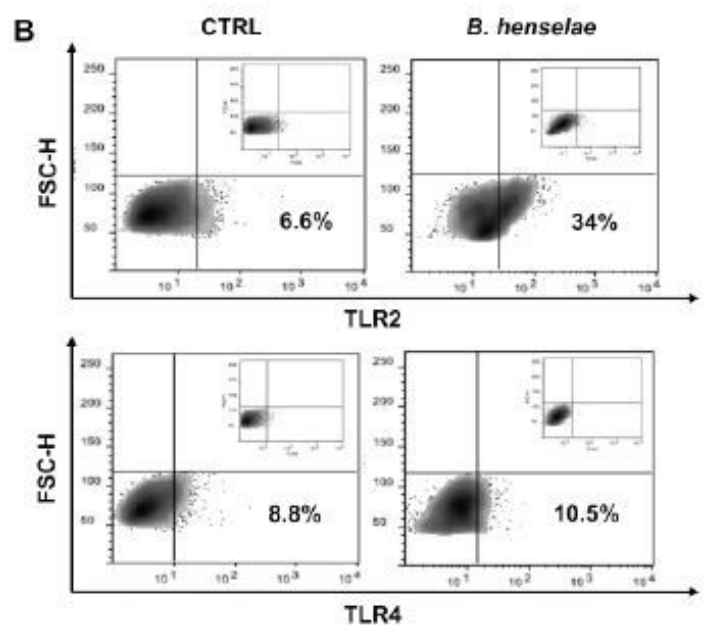

E
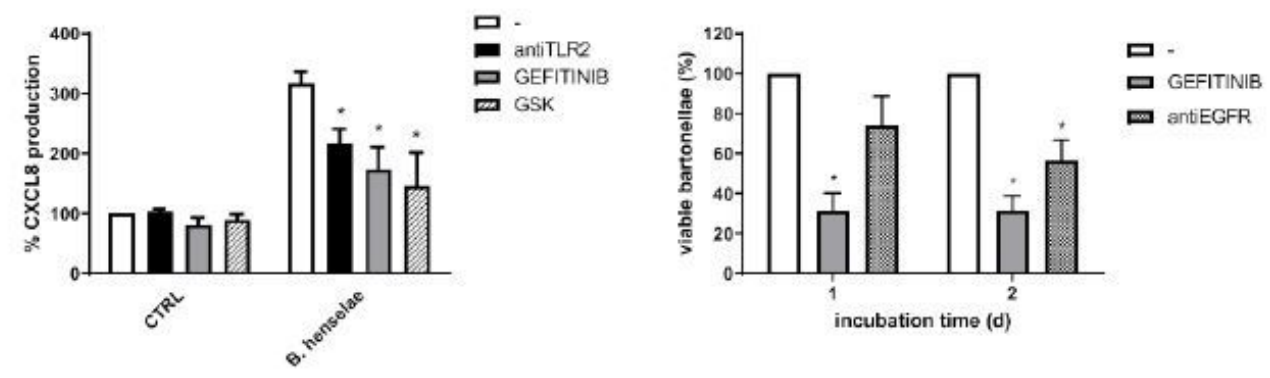

Figure 4

Expression of TLR2, NOD1 and EGFR in B. henselae-infected MSCs. (A) mRNA expression levels of TLR2, TLR4, NOD1 and EGFR in uninfected (white bar) and B. henselae-infected MSCs (black bar) were determined by qPCR and normalized to RPL13A. Data are expressed as means \pm SEM of four independent experiments ( $\mathrm{P}<0.05$; unpaired t-test). (B) TLR2 and TLR4 protein expression levels on MSC membranes were analyzed by FACS in MSCs at $4 \mathrm{~d}$ pi. Cells were immunostained with anti-TLR2, anti-TLR4 or specific isotype control antibodies. The percentages of positive cells are indicated in each quadrant. Fluorescence minus one (FMO) controls for the antibodies are shown as well. Data are representative of three independent experiments. (C) Cell extracts from MSCs infected with B. henselae 
for 30,60 , and 120 min or with hEGF $(50 \mathrm{ng} / \mathrm{mL})$ for 15 min were subjected to immunoblotting using antiEGFR pY1068 or anti-EGFR antibodies. (D) Analysis of CXCL8 in the supernatants from uninfected or B. henselae-infected MSCs pre-treated or not for $6 \mathrm{~h}$ with a neutralizing anti-TLR2 antibody $(10 \mu \mathrm{g} / \mathrm{mL})$ or with the EGFR inhibitor gefitinib $(10 \mu \mathrm{M})$ or the RIP2K inhibitor GSK583 $(1 \mu \mathrm{M})$ and then stimulated for 96 h. Data are shown as percentage (Mean \pm SEM) of CXCL8 production compared to DMSO or specific isotype control antibody-treated cells set at $100 \%$ ( $n=6$ for antiTLR2; $n=4$ for gefitinib, $n=3$ for GSK583; *P $<0.05$ vs $B$. henselae-infected cells; unpaired t-test). (E) To evaluate $B$. henselae internalization, MSC were pretreated for $6 \mathrm{~h}$ with the neutralizing anti-EGFR $(10 \mu \mathrm{g} / \mathrm{mL})$ or gefitinib $(10 \mu \mathrm{M})$, and percentages of intracellular bacteria were determined, after 1 and 2 days of incubation, respect to DMSO or specific isotype control antibody-treated cells set at $100 \%$. Data are shown as mean \pm SEM ( $n=4$ for gefitinib, $n=2$ for EGFR experiments performed in duplicate; ${ }^{*} \mathrm{P}<0.05$ vs internalized bacteria in untreated cells; unpaired t-test).

A
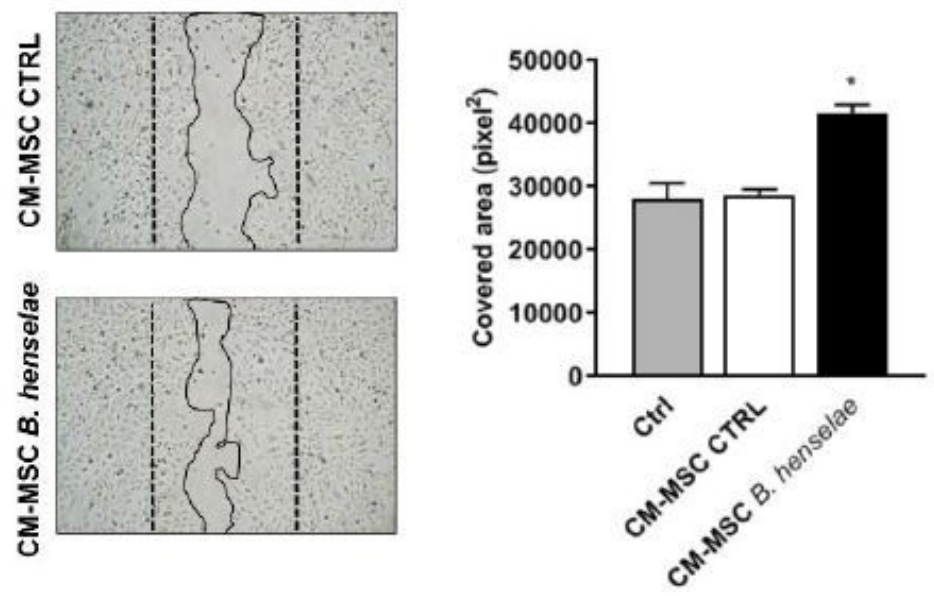

C
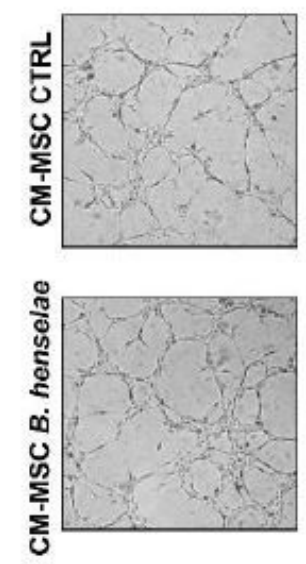

B
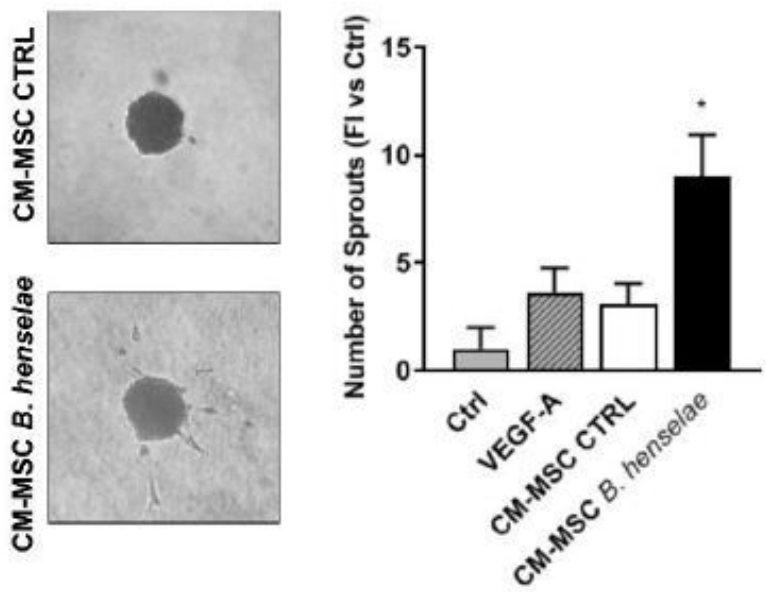

D

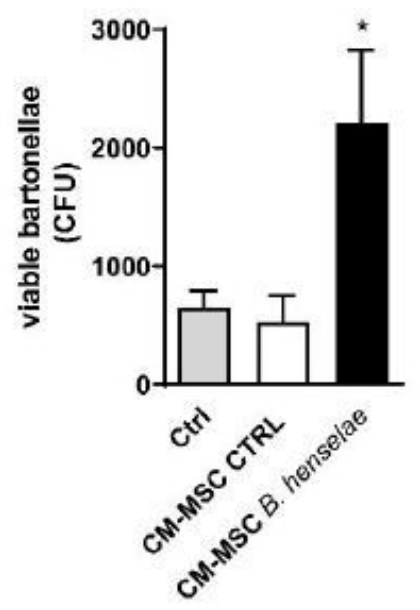

Figure 5

Conditioned medium from B. henselae-infected MSCs curbs the infection rates and angiogenic response of HUVECs. The effects of conditioned medium (CM) from B. henselae-infected MSCs were tested by means of different angiogenic assays. (A) HUVEC monolayers were wounded with a 1.0-mm-wide rubber 
policeman and incubated in fresh medium supplemented with 5\% FCS and 1:2 diluted CM from infected (black bar, CM-MSC CTRL) or uninfected (white bar, CM-MSC B. henselae) MSCs. After 1 day, HUVECs invading the wound were quantified by digital imaging. Mean \pm SEM of 4 measurements per sample. ${ }^{*} \mathrm{P}$ 0.05 vs Ctrl; unpaired t-test. (B) Sprouting analysis of HUVEC spheroids. Spheroids were prepared in $20 \%$ methylcellulose medium, embedded in fibrin gel and stimulated with 1:2 diluted CM obtained from MSCs treated in the presence (black bar) or absence (white bar) of bacteria or with $30 \mathrm{ng} / \mathrm{ml}$ VEGF-A (dashed bar). The number of growing cell sprouts was counted after 1 day. Data are expressed as mean \pm SEM $(n=10-20)$ and indicated as fold increase in the number of sprouts/spheroid vs Ctrl. *P $<0.05 v s$ Ctrl; unpaired t-test. (C) The effect of CM from uninfected vs B. henselae-infected MSCs on HUVEC morphogenesis was assessed by tube morphogenesis assay in three-dimensional (3D) collagen matrix. HUVECs were seeded (40000 cells/cm2) on Cultrex Extracellular Matrix in the presence of 1:2 diluted CM from uninfected (white bar) or B. henselae-infected MSCs (black bar). After $8 \mathrm{~h}$, the formation of capillarylike structures was examined. Representative images are shown in the left panels. The quantifications of capillary-like structure (right panel) are expressed as means \pm SEM relative to three measurements per sample. * $\mathrm{P}<0.05$ vs Ctrl; unpaired t-test. (D) Invasion rate of B. henselae in HUVECs (expressed as total CFUs) after 1 day of infection in the absence (grey bar) or presence of 1:2 diluted CM-MSC CTRL (white bar) and CM-MSC B. henselae (black bar). * $\mathrm{P}<0.05$; unpaired t-test.

A
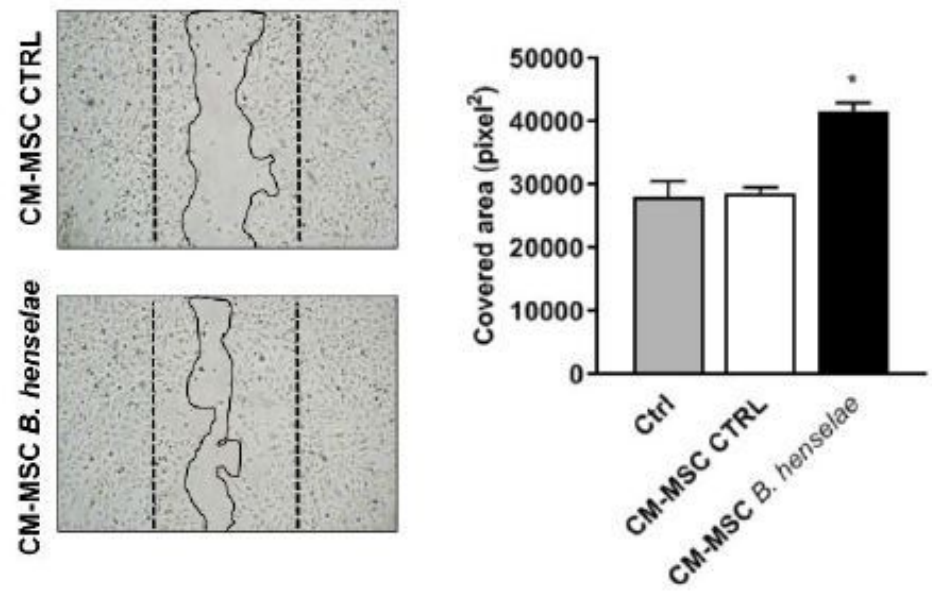

C

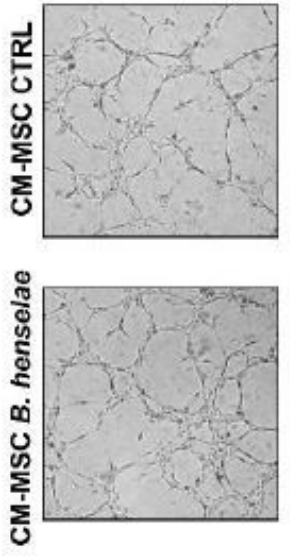

B
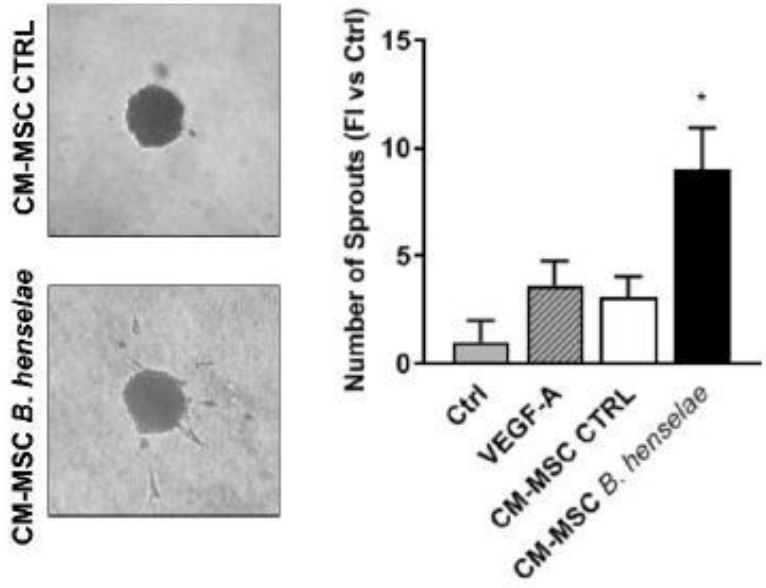

D

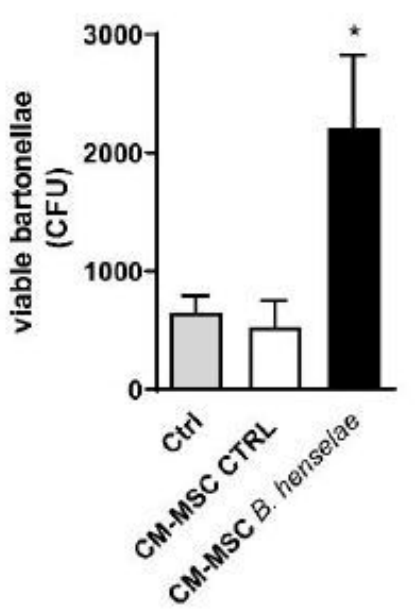




\section{Figure 5}

Conditioned medium from $B$. henselae-infected MSCs curbs the infection rates and angiogenic response of HUVECs. The effects of conditioned medium (CM) from B. henselae-infected MSCs were tested by means of different angiogenic assays. (A) HUVEC monolayers were wounded with a 1.0-mm-wide rubber policeman and incubated in fresh medium supplemented with $5 \%$ FCS and 1:2 diluted CM from infected (black bar, CM-MSC CTRL) or uninfected (white bar, CM-MSC B. henselae) MSCs. After 1 day, HUVECs invading the wound were quantified by digital imaging. Mean \pm SEM of 4 measurements per sample. *P < 0.05 vs Ctrl; unpaired t-test. (B) Sprouting analysis of HUVEC spheroids. Spheroids were prepared in $20 \%$ methylcellulose medium, embedded in fibrin gel and stimulated with 1:2 diluted CM obtained from MSCs treated in the presence (black bar) or absence (white bar) of bacteria or with $30 \mathrm{ng} / \mathrm{ml}$ VEGF-A (dashed bar). The number of growing cell sprouts was counted after 1 day. Data are expressed as mean \pm SEM $(n=10-20)$ and indicated as fold increase in the number of sprouts/spheroid vs Ctrl. * $P<0.05 v s$ Ctrl; unpaired t-test. (C) The effect of CM from uninfected vs B. henselae-infected MSCs on HUVEC morphogenesis was assessed by tube morphogenesis assay in three-dimensional (3D) collagen matrix. HUVECs were seeded (40000 cells/cm2) on Cultrex Extracellular Matrix in the presence of 1:2 diluted CM from uninfected (white bar) or B. henselae-infected MSCs (black bar). After $8 \mathrm{~h}$, the formation of capillarylike structures was examined. Representative images are shown in the left panels. The quantifications of capillary-like structure (right panel) are expressed as means \pm SEM relative to three measurements per sample. * $P<0.05$ vs Ctrl; unpaired t-test. (D) Invasion rate of B. henselae in HUVECs (expressed as total CFUs) after 1 day of infection in the absence (grey bar) or presence of 1:2 diluted CM-MSC CTRL (white bar) and CM-MSC B. henselae (black bar). ${ }^{*} \mathrm{P}<0.05$; unpaired t-test. 
A
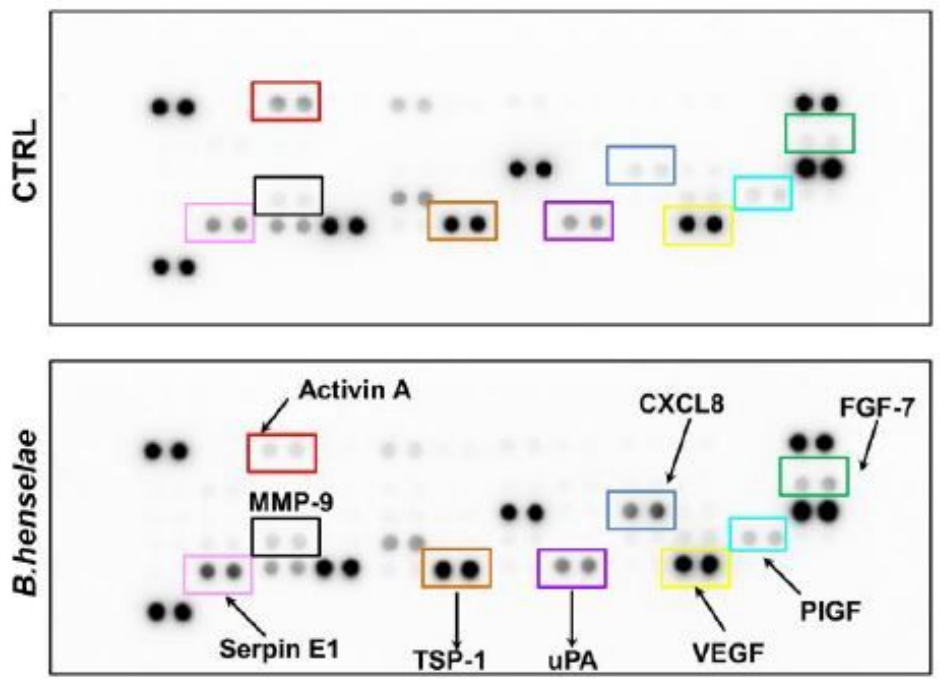

C

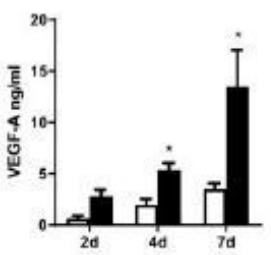

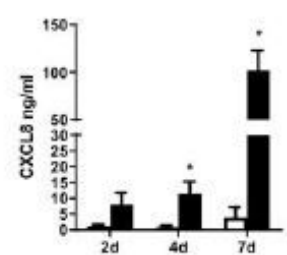

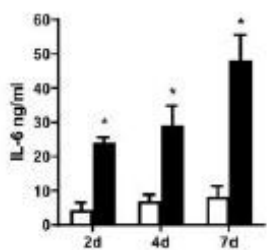

B
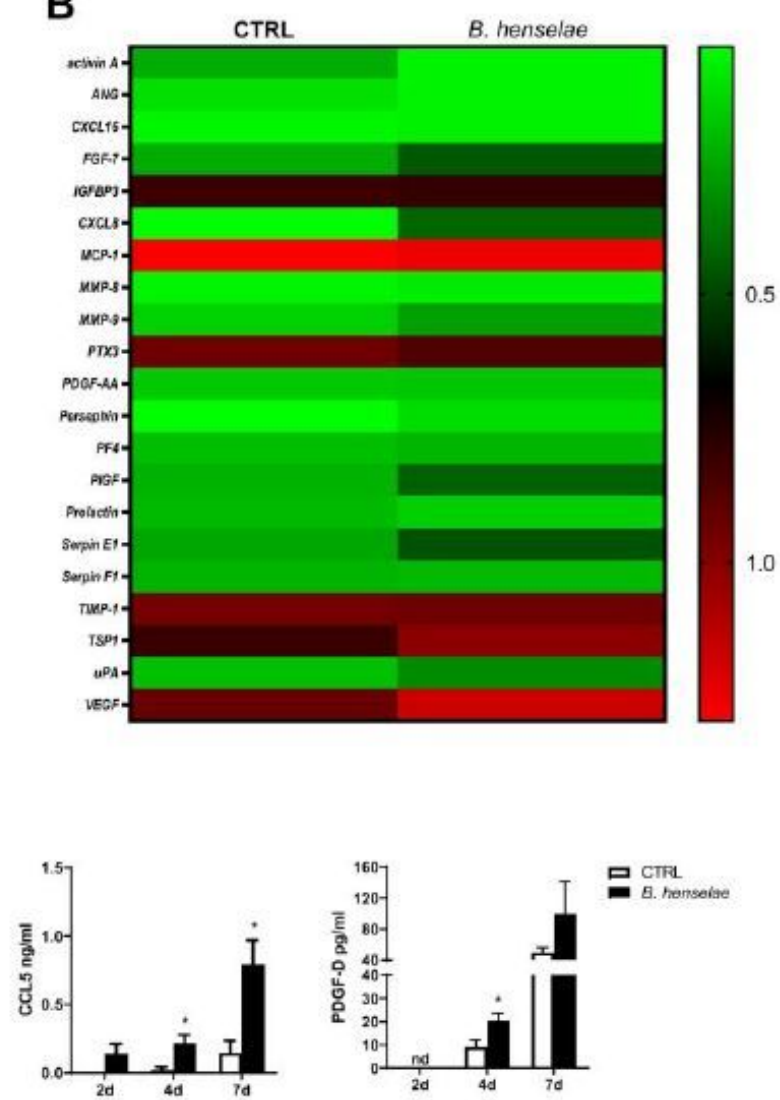

Figure 6

Angiogenic signature of B. henselae-infected MSCs. (A) Human angiogenesis antibody array analysis was performed using a pool of supernatants from $96 \mathrm{~h}$ uninfected MSC (CTRL) or B. henselae-infected MSCs. Some of the most representative angiogenic factors are highlighted in different colors. The graph with normalized pixel density of all the visualized spots is shown in Fig. S1 in the supplemental material. (B) Heat map analysis representing the normalized average pixel density of the pair of duplicate spots for each angiogenic-related protein in the array. (C) Quantification of VEGF-A, CXCL8, IL-6, CCL5 and PDGF-D production in uninfected (CTRL) and B. henselae-infected MSCs. Data are expressed as mean \pm SEM of 3 independent experiments. ${ }^{*} \mathrm{P}<0.05$ vs $\mathrm{CTRL}$; unpaired t-test. $\mathrm{nd}=$ not detectable. 
A
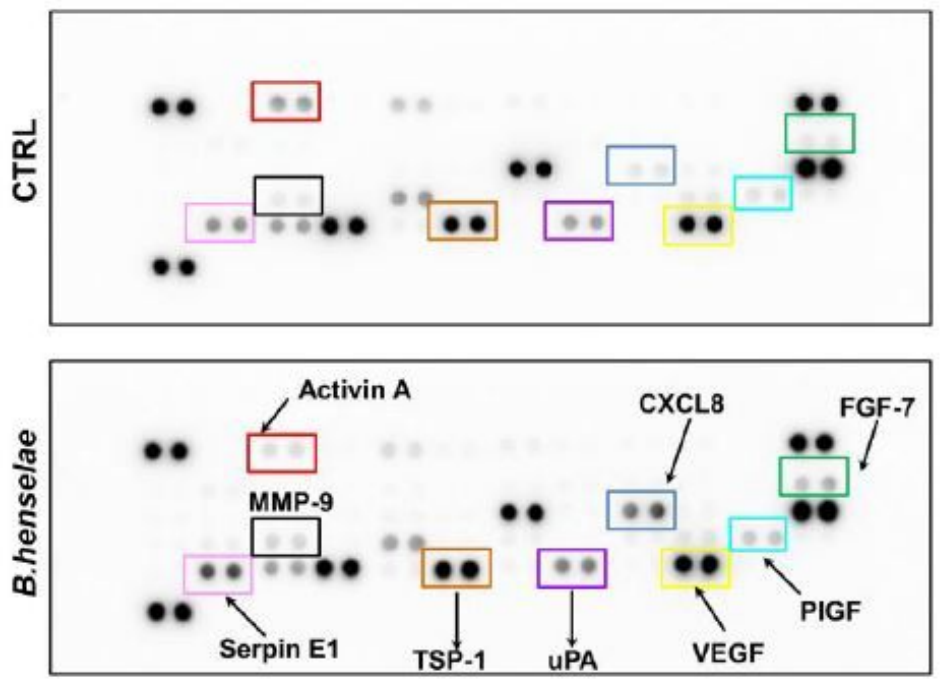

C

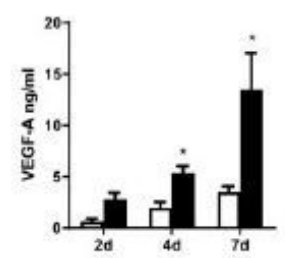

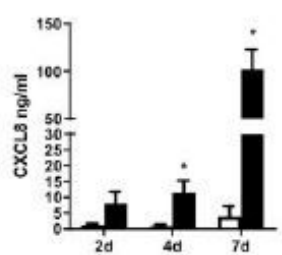

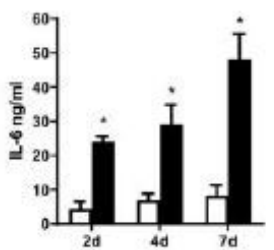

B
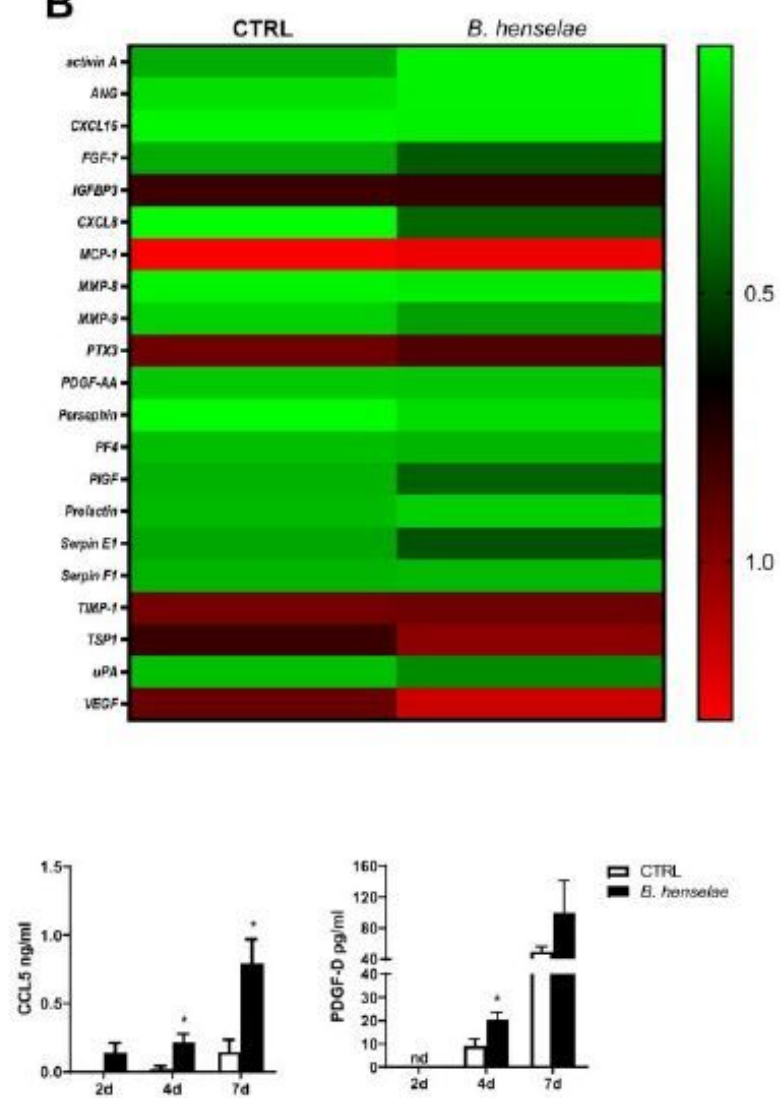

Figure 6

Angiogenic signature of B. henselae-infected MSCs. (A) Human angiogenesis antibody array analysis was performed using a pool of supernatants from $96 \mathrm{~h}$ uninfected MSC (CTRL) or B. henselae-infected MSCs. Some of the most representative angiogenic factors are highlighted in different colors. The graph with normalized pixel density of all the visualized spots is shown in Fig. S1 in the supplemental material. (B) Heat map analysis representing the normalized average pixel density of the pair of duplicate spots for each angiogenic-related protein in the array. (C) Quantification of VEGF-A, CXCL8, IL-6, CCL5 and PDGF-D production in uninfected (CTRL) and B. henselae-infected MSCs. Data are expressed as mean \pm SEM of 3 independent experiments. ${ }^{*} \mathrm{P}<0.05$ vs $\mathrm{CTRL}$; unpaired t-test. nd= not detectable.

\section{Supplementary Files}

This is a list of supplementary files associated with this preprint. Click to download.

- AdditionalFile1.pdf

- AdditionalFile1.pdf 